\title{
Instantaneous longwave radiative impact of ozone: an application on IASI/MetOp observations
}

\author{
S. Doniki ${ }^{1}$, D. Hurtmans ${ }^{1}$, L. Clarisse ${ }^{1}$, C. Clerbaux ${ }^{1,2}$, H. M. Worden ${ }^{3}$, K. W. Bowman ${ }^{4}$, and P.-F. Coheur ${ }^{1}$ \\ ${ }^{1}$ Spectroscopie de l'Atmosphère, Service de Chimie Quantique et Photophysique, Université Libre de Bruxelles (ULB), \\ Brussels, Belgium \\ ${ }^{2}$ Sorbonne Universités, UPMC Université Paris 06, Université Versailles St.-Quentin, CNRS/INSU, LATMOS-IPSL, \\ Paris, France \\ ${ }^{3}$ Atmospheric Chemistry Observations \& Modeling (ACOM) Laboratory, National Center of Atmospheric Research (NCAR), \\ Boulder, Colorado, USA \\ ${ }^{4}$ Jet Propulsion Laboratory (JPL), California Institute of Technology, Pasadena, California, USA
}

Correspondence to: S. Doniki (sdoniki@ulb.ac.be)

Received: 3 June 2015 - Published in Atmos. Chem. Phys. Discuss.: 6 August 2015

Revised: 4 November 2015 - Accepted: 9 November 2015 - Published: 24 November 2015

\begin{abstract}
Ozone is an important greenhouse gas in terms of anthropogenic radiative forcing (RF). RF calculations for ozone were until recently entirely model based, and significant discrepancies were reported due to different model characteristics. However, new instantaneous radiative kernels (IRKs) calculated from hyperspectral thermal IR satellites have been able to help adjudicate between different climate model RF calculations. IRKs are defined as the sensitivity of the outgoing longwave radiation (OLR) flux with respect to the ozone vertical distribution in the full $9.6 \mu \mathrm{m}$ band. Previous methods applied to measurements from the Tropospheric Emission Spectrometer (TES) on Aura rely on an anisotropy approximation for the angular integration. In this paper, we present a more accurate but more computationally expensive method to calculate these kernels. The method of direct integration is based on similar principles to the anisotropy approximation, but it deals more precisely with the integration of the Jacobians. We describe both methods and highlight their differences with respect to the IRKs and the ozone longwave radiative effect (LWRE), i.e., the radiative impact in OLR due to absorption by ozone, for both tropospheric and total columns, from measurements of the Infrared Atmospheric Sounding Interferometer (IASI) onboard MetOp-A. Biases between the two methods vary from -25 to $+20 \%$ for the LWRE, depending on the viewing angle. These biases point to the inadequacy of the anisotropy method, especially at nadir, suggesting that the TES-derived LWREs are biased
\end{abstract}

low by around $25 \%$ and that chemistry-climate model OLR biases with respect to TES are underestimated. In this paper we also exploit the sampling performance of IASI to obtain first daily global distributions of the LWRE, for 12 days (the 15th of each month) in 2011, calculated with the direct integration method. We show that the temporal variation of global and latitudinal averages of the LWRE shows patterns which are controlled by changes in the surface temperature and ozone variation due to specific processes, such as the ozone hole in the polar regions and stratospheric intrusions into the troposphere.

\section{Introduction}

Ozone in the atmosphere is a key substance for both atmospheric chemistry and climate. It is a secondary pollutant, the abundance of which is controlled by the emissions of its precursors, the availability of oxidizing agents and sunlight, and the availability of ozone-depleting substances (ODSs). Ozone is also a highly radiatively active gas for both solar (shortwave, SW) and terrestrial (longwave, LW) radiation. Even small changes in the atmospheric distribution of ozone have an impact on the radiative forcing (RF) of climate (e.g., Forster et al., 2007). To understand and accurately represent the impact of ozone on climate, a good knowledge of the ozone distribution is required, both horizontally and verti- 
cally, as well as its long-term trends, both in the troposphere and the stratosphere. Especially in the troposphere, ozone acts as a greenhouse gas (GHG), while its amount has substantially increased since pre-industrial times, due to increase of precursor emissions. Nowadays tropospheric ozone is the third-most-important GHG in terms of radiative forcing, after the well-mixed GHGs (Myhre et al., 2013); however it is distinguished from the other GHGs due to its high spatial and temporal variability, caused by its relatively short lifetime.

It is well known that ozone RF is strongly dependent on its vertical distribution, as well on the surface temperature and the vertical profiles of temperature, humidity and clouds (e.g., Lacis et al., 1990; Forster and Shine, 1997; Gauss et al., 2003; Worden et al., 2008, 2011; Bowman et al., 2013). Ozone RF calculations and changes over time are entirely model based since no ozone records are available for the preindustrial era. These calculations depend on the assumptions and radiative transfer code of each model, leading to intermodel discrepancies. According to the latest IPCC assessment report (IPCC AR5) (Myhre et al., 2013), the contribution of anthropogenic tropospheric ozone to RF is around $+0.40 \mathrm{~W} \mathrm{~m}^{-2}\left(+0.20\right.$ to $\left.+0.60 \mathrm{~W} \mathrm{~m}^{-2}\right)$, with this value representing the ensemble of model calculations. For the time period of 1750 to 2011, studied in the IPCC AR5, Søvde et al. (2011) report a value of $+0.45 \mathrm{~W} \mathrm{~m}^{-2}$ for tropospheric ozone, while Skeie et al. (2011) report a slightly lower value of $+0.41 \mathrm{~W} \mathrm{~m}^{-2}$ (0.21 to 0.61$)$, the same as Stevenson et al. (2013) under the Atmospheric Chemistry and Climate Model Intercomparison Project (ACCMIP). Stratospheric ozone has less impact on the RF: the IPCC reports a value of $-0.05 \pm 0.1 \mathrm{~W} \mathrm{~m}^{-2}$ (Myhre et al., 2013), while Conley et al. (2013) for the ACCMIP report a RF of $-0.02 \mathrm{~W} \mathrm{~m}^{-2}$ ( -0.09 to 0.05 ). Stratospheric ozone RF is not much affected by recent changes in concentrations (following for instance a decrease in emissions of ODSs). Confidence intervals remain quite large in all studies, with questionable reliability, since until recently the present-day components of these estimates could not be tested against observations on large scales.

Satellite measurements of vertical distribution of ozone on the global scale have started to be available in the last decade, but there are only a few previous studies that have used these satellite data for quantifying the radiative effect of ozone (Worden et al., 2008; Joiner et al., 2009). Particularly attractive in this context are infrared nadir sounders, which have sufficient vertical sensitivity to distinguish tropospheric and stratospheric ozone distributions and allow direct measurements of the top-of-the-atmosphere (TOA) radiance in the IR ozone band globally, with high sampling. In 2011, Worden et al. (2011) used the measurements of Aura-TES (Tropospheric Emission Spectrometer) to calculate the longwave radiative effect (LWRE) due to ozone with respect to TOA radiative flux. This radiative effect is different from the radiative forcing defined in IPCC (Ramaswamy et al., 2001), as it is not calculated at the tropopause and does not refer to ozone concentration changes with respect to pre-industrial levels. Worden et al. (2011) introduced the innovative concept of instantaneous radiative kernel (IRK), which represents the sensitivity of the TOA radiative flux with respect to the observed ozone profile in the $9.6 \mu \mathrm{m}$ ozone band. With the IRK it is possible to calculate the longwave radiative effect due to ozone in each atmospheric layer. Aghedo et al. (2011) used the IRKs from TES to evaluate the ozone radiative impact of model ozone biases from chemistry-climate models included in ACCMIP. Bowman et al. (2013) revealed a correlation between model outgoing longwave radiation (OLR) bias and RF in the ACCMIP models. This correlation was used to reduce the intermodel spread in RF by around $30 \%$ (Myhre et al., 2013). Both studies have revealed that models show large biases locally, especially in the tropics, but that globally the agreement is better due to compensating errors. These studies show that small biases in the vertical structure of ozone can accumulate to large biases in OLR, with implications in the radiative forcing used by the IPCC.

In this paper we use IASI observations to obtain the first daily global distributions of the ozone's IRKs and LWRE. IASI achieves nearly global coverage owing to a $2200 \mathrm{~km}$ large swath (scanning angle ranging from -48 to $48^{\circ}$ ). Here we developed a new retrieval methodology (called the direct integration method) to deal with the off-nadir angles. Even though the method is computationally expensive, it is significantly more accurate than the TOA anisotropy method used in Worden et al. (2011) and subsequent studies with TES, even for the nadir view.

The paper is organized as follows. Section 2 presents IASI and its characteristics. Section 3 describes the Fast Optimal Retrieval on Layers for IASI (FORLI), the ozone retrieval algorithm for IASI developed at the Université Libre de Bruxelles (ULB), and additional calculations that were implemented into FORLI to assist the computations of IRKs and LWRE. In Sect. 4 we describe both methods for computing the IRKs and highlight the differences between them. In Sect. 5 we provide and analyze the LWRE for both tropospheric and total ozone obtained from IASI. This is achieved for the two integration methods, and the results are discussed on this basis. We underline the bias of the anisotropy method and previous measurements of LWRE from TES. Finally, using 12 days of observations in 2011, we provide a first analysis of the LWRE seasonal variation on the globe. The conclusions and summary are given in Sect. 6.

\section{IASI}

IASI is a Michelson interferometer onboard the MetOp$\mathrm{A}$ and $\mathrm{B}$ satellites that is designed to measure the radiation emitted by the Earth and the atmosphere in the thermal infrared (TIR) spectral range (Clerbaux et al., 2009). MetOpA and B - launched in October 2007 and September 2012, respectively, with a third one scheduled for 2018 - are polar- 
orbiting, sun-synchronous satellites, with Equator-crossing times around 09:30 and 21:30 LT. IASI uses nadir geometry, complemented by off-nadir measurements up to $48.3^{\circ}$ on both sides of the satellite track (swath of $\sim 2200 \mathrm{~km}$ ), in such a way that the instrument covers the globe twice a day, providing a total of around 1.3 million observations. Each instantaneous field of view of IASI is composed of $2 \times 2$ circular pixels, and each pixel has a $12 \mathrm{~km}$ diameter footprint on the ground at nadir. IASI covers the spectral range from 645 to $2760 \mathrm{~cm}^{-1}$, with a $0.25 \mathrm{~cm}^{-1}$ sampling $\left(0.5 \mathrm{~cm}^{-1}\right.$ apodized resolution for the Level $1 \mathrm{C}$ data) and radiometric noise between 0.25 and $0.3 \mathrm{~K}$ around $1000 \mathrm{~cm}^{-1}$ at a reference temperature of $280 \mathrm{~K}$.

The primary goal of IASI is to provide data of high radiometric quality to improve numerical weather prediction (Hilton et al., 2011). In addition to the weather-related information, IASI was also designed to provide high-quality measurements for atmospheric composition monitoring. The instrument has already proved its capabilities by measuring not only global distributions and time series of some strong absorbers such as $\mathrm{CO}, \mathrm{CO}_{2}, \mathrm{CH}_{4}, \mathrm{O}_{3}$ and $\mathrm{H}_{2} \mathrm{O}$ but also shortlived species such as $\mathrm{SO}_{2}, \mathrm{NH}_{3}, \mathrm{CH}_{3} \mathrm{OH}, \mathrm{HCOOH}$ and others (Clerbaux et al., 2009; Coheur et al., 2009; Clarisse et al., 2011; Hilton et al., 2011). IASI provides also information concerning cloud and aerosol properties and surface emissivity, and it contributes to climate-related programs such as the Global Climate Observing System (GCOS/WMO; http: //www.wmo.int/pages/prog/gcos/) (Hilton et al., 2011).

\section{Calculations with FORLI}

FORLI is a radiative transfer and retrieval software built at ULB to serve the atmospheric composition objectives of the IASI mission. FORLI is running at ULB in near-real time, providing total columns and vertical profiles of $\mathrm{O}_{3}, \mathrm{CO}$ and $\mathrm{HNO}_{3}$ for each Level $1 \mathrm{C}$ observation (observed spectrum after applying geolocation, calibration, resampling, apodization and quality control, as indicated in EUMETSAT, 2014). The retrieval algorithm is based on the maximum a posteriori solution as described in Rodgers (2000), also known as the optimal estimation method (OEM). A detailed description of FORLI, methods, input parameters and approximations can be found in Hurtmans et al. (2012). The main elements for the ozone retrievals are given below.

The ozone product of FORLI (version v20100815) is retrieved in the spectral range of $1025-1075 \mathrm{~cm}^{-1}$, which contains most information on the ozone vertical distribution. Note that the spectral range also includes a few water vapor lines and a small contribution of methanol. For the retrieval the model uses pre-calculated tables (LUTs) of $\mathrm{O}_{3}$ absorbance at different pressures, temperatures and humidity, which were computed initially using the line parameters from the HITRAN 2004 database (Rothman et al., 2005). It also uses as input for each pixel the temperature and humid- ity profiles and the cloud fraction, retrieved at EUMETSAT from the IASI Level 2 Product Processing Facility (August et al., 2012) and disseminated in near-real time through the EUMETCast system. Only scenes with less than $13 \%$ cloud coverage (clear sky) are processed for ozone, of which only those that pass a posteriori quality checks are finally selected. The output consists of the ozone profile in a vertical grid of 40 layers between the surface and $40 \mathrm{~km}$, with one more layer from $40 \mathrm{~km}$ to TOA, along with the averaging kernels and the relative total error profile on the same grid. Surface temperature and total column of water vapor are also retrieved simultaneously.

To obtain the IRKs and LWRE, from the retrieved ozone profile, we re-compute the spectrum and the corresponding Jacobians in a broader band $\left(985-1080 \mathrm{~cm}^{-1}\right.$, which includes the full $9.6 \mu \mathrm{m}$ band), in an additional step after the last iteration. As noted above, for the retrieval FORLI uses a limited band, which nevertheless contains most of the information on the ozone vertical distribution. However, as we show in Sect. 4, the calculation of the IRKs, and consequently of the LWRE, is based on the integral over the wavenumber, among others. Thus, it is most appropriate to use the full ozone band to avoid underestimations. Furthermore, since the IRKs and LWRE are strongly dependent on the spectrum itself, we perform these forward calculations at a high spectral sampling of $0.0025 \mathrm{~cm}^{-1}$. We found that performing these calculations at the IASI sampling $\left(0.25 \mathrm{~cm}^{-1}\right)$ caused differences up to $20 \%$ in the final LWRE.

Previous studies describing ozone profiles and columns retrieved from the IASI measurements have shown that, for a profile, 2.5 to 4 independent pieces of information can be retrieved. These independent pieces of information, also known as degrees of freedom for signal (DOFs), are the trace of the averaging kernels matrix (AVKs) (see Rodgers, 2000, for details). The maximum sensitivity, which can be obtained by the peak of the AVKs, is found from the mid-troposphere to the mid-stratosphere, allowing tropospheric and stratospheric ozone to be derived almost independently (e.g., Boynard et al., 2009; Wespes et al., 2012; Safieddine et al., 2014). Some information is also available on the lower tropospheric levels, mostly in summer during daytime. The error budget is dominated by the smoothing error, with some contribution from the retrieval error, which includes the quality of the spectral fit (root mean square (rms) of the observed minus the calculated radiance), spectroscopic and forward model errors (Boynard et al., 2009). For a single IASI-FORLI measurement the uncertainty is estimated to be $\pm 15 \%$ for the tropospheric column and to $\pm 7 \%$ for the total column of ozone (Hurtmans et al., 2012).

For this study we used an updated version of FORLI, with the LUTs recalculated to cover the spectral band from 960 to $1105 \mathrm{~cm}^{-1}$ and updated using HITRAN 2012 (Rothman et al., 2013) instead of HITRAN 2004. The updated spectroscopic line list was used in an effort to reduce biases in the $\mathrm{O}_{3}$ product. Indeed, comparisons of the previous product with 
ground-based, sonde and satellite data (e.g., Boynard et al., 2009; Scannell et al., 2012; Dufour et al., 2012; Gazeaux et al., 2013) showed that the retrieved ozone total column using the thermal infrared spectral range seemed to be biased high by $3-4 \%$, with some larger differences at high latitudes. The comparison with sonde data also shows a systematic bias of $1.6 \%$ for the tropospheric column and $2-3 \%$ for the stratospheric column. Moreover, a mean systematic bias of around $10 \%$ is found in the upper troposphere-lower stratosphere (UTLS), reaching $25 \%$ at $10 \mathrm{~km}$, which is common to different algorithms and retrieval schemes (Dufour et al., 2012), possibly indicating issues with the $\mathrm{O}_{3}$ spectroscopy around $9.6 \mu \mathrm{m}$. With the updated spectroscopy, there is preliminary evidence that retrieved $\mathrm{O}_{3}$ columns are lower by 4-5\%, which would largely improve the comparisons with Brewer spectrometers and the UV-satellite sensors.

\section{IASI instantaneous radiative kernels}

In this section we will outline the different methods for calculating the IRKs and LWRE. We begin with a couple of definitions. The TOA flux, $F_{\mathrm{TOA}}$ (in $\mathrm{W} \mathrm{m}^{-2}$ ), is defined (Suttles et al., 1988) as

$$
\begin{aligned}
F_{\mathrm{TOA}} & =\int_{v_{1}}^{v_{2}} \int_{0}^{2 \pi} \int_{0}^{\pi / 2} L_{\mathrm{TOA}}(v, \theta, \phi) \cos \theta \sin \theta \mathrm{d} \theta \mathrm{d} \phi \mathrm{d} v \\
& =2 \pi \int_{v_{1}}^{v_{2}} \int_{0}^{\pi / 2} L_{\mathrm{TOA}}(v, \theta) \cos \theta \sin \theta \mathrm{d} \theta \mathrm{d} v,
\end{aligned}
$$

with $L_{\mathrm{TOA}}(v, \theta, \phi)$ being the upwelling TOA radiance at the zenith angle $\theta$, azimuth angle $\varphi$, and wavenumber $v$ (where $v_{1}=985$ and $v_{2}=1080 \mathrm{~cm}^{-1}$ in our study). In the last equation we assumed azimuthal symmetry, in which case the integral over the angle $\varphi$ reduces to $2 \pi$ (Suttles et al., 1988; Loeb et al., 2003). The IRK (in $\mathrm{Wm}^{-2} \mathrm{ppb}^{-1}$ ) (Worden et al., 2011) represents the sensitivity of $F_{\mathrm{TOA}}$ to a change in the vertical distribution of an atmospheric parameter and is defined by

$$
\frac{\partial F_{\mathrm{TOA}}}{\partial q\left(z_{l}\right)}=2 \pi \int_{v_{1}}^{v_{2}} \int_{0}^{\pi / 2} \frac{\partial L_{\mathrm{TOA}}(v, \theta)}{\partial q\left(z_{l}\right)} \cos \theta \sin \theta \mathrm{d} \theta \mathrm{d} v
$$

where $q\left(z_{l}\right)$ is the atmospheric parameter at mean altitude $z$ of layer $l$ (the ozone abundance in our study). Note that all zenith angles are converted to equivalent TOA nadir angles for IASI and will be used as such hereafter.

\subsection{IASI-FORLI radiance Jacobians}

The analytic Jacobians $\partial L_{\mathrm{TOA}}(v, \theta) / \partial q\left(z_{l}\right)$ represent the sensitivity of the IASI TOA spectral radiances, measured with different angles along the swath, to the ozone

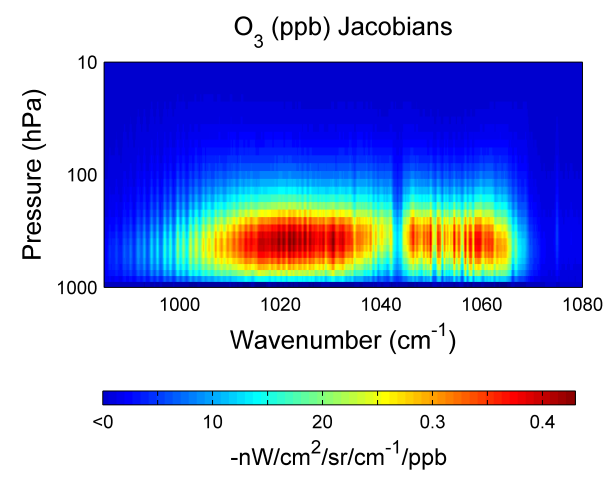

Figure 1. Example of $\mathrm{O}_{3}$ Jacobians for a single observation in the $9.6 \mu \mathrm{m}$ spectral band, with respect to ozone in $\mathrm{ppb}$ for an observation taken on 15 January 2011 , at $\left(51.13^{\circ} \mathrm{N}, 42.3^{\circ} \mathrm{W}\right)$ and 04:57 UTC and for $47.48^{\circ}$ viewing angle.

abundance at each vertical level. They have units of $\mathrm{W} \mathrm{cm}{ }^{-2} \mathrm{sr}^{-1} \mathrm{~cm} \mathrm{ppb}^{-1}$ and correspond to layer averaged values, which are each assigned to the mean altitude - or corresponding pressure - of each layer. For most layers, air temperature is lower than the surface temperature and Jacobians have a negative sign, as we follow the convention that an increase in the abundance of the absorbing gas results in a reduced TOA radiance. Note also that the units of the retrieved parameter may vary; e.g., ozone can be represented in units of volume mixing ratio (VMR, in ppb), $\ln (\mathrm{VMR})$, or Dobson units (DU). The Jacobians can be obtained or converted with respect to the preferred units, which however will have an impact to the altitude of the maximum sensitivity.

As an example, Fig. 1 shows the IASI-FORLI radiance Jacobians for ozone with respect to VMR (ppb). The Jacobian is found to peak in the mid- and upper troposphere, around 600 to $250 \mathrm{hPa}$. These results for IASI are in agreement with previous studies and are explained by the fact that thermal IR instruments have in general their highest sensitivity to the ozone profile in the mid-troposphere (Bowman et al., 2002; Coheur et al., 2005; Boynard et al., 2009; Worden et al., 2011). Interfering water vapor and methanol lines have little impact on the ozone sensitivity, since the high spectral sampling of IASI allows the spectral distinction between the different species.

\subsection{Angular integration of moments}

The angular integral in Eq. (1) can be approximated to arbitrary precision using the Gaussian quadrature (GQ) (Abramowitz and Stegun, 1972; Li, 2000), where the integral is replaced by a sum over a finite number of angles. In particular, for a function $g(\theta)$, the integral over $g(\theta) \cos (\theta) \sin (\theta)$ can be written using the GQ as 
Table 1. Zenith angle, cosine of zenith angle, equivalent TOA nadir angle for IASI and corresponding weight for the five-node GQ.

\begin{tabular}{cccc}
\hline $\begin{array}{c}\text { Zenith angle }\left(^{\circ}\right) \\
\theta_{i}\end{array}$ & $x_{i}=\cos \theta_{i}$ & TOA nadir angle $\left(^{\circ}\right)$ & Weight, $w_{i}$ \\
\hline 84.3452 & 0.098535 & 61.2563 & 0.015748 \\
72.2698 & 0.304536 & 57.0576 & 0.073909 \\
55.8040 & 0.562025 & 46.7816 & 0.146387 \\
36.6798 & 0.801987 & 31.7557 & 0.167175 \\
16.2213 & 0.960190 & 14.2483 & 0.096782 \\
\hline
\end{tabular}

$$
\begin{aligned}
\int_{0}^{\pi / 2} g(\theta) \cos \theta \sin \theta \mathrm{d} \theta & =\int_{0}^{1} g\left(\cos ^{-1} x\right) x \mathrm{~d} x \\
& =\int_{0}^{1} x^{k} f(x) \mathrm{d} x \approx \sum_{i=1}^{n} w_{i} f\left(x_{i}\right),
\end{aligned}
$$

with $x=\cos \theta$ and $\mathrm{d} x=-\sin \theta \mathrm{d} \theta$. The GQ parameters $x_{i}=$ $\cos \theta_{i}, \theta_{i}$ and weights $w_{i}$ are provided in Table 1 for the first order of moment $(k=1)$ and for five nodes $(n=5)$.

\subsection{Anisotropy approximation}

The anisotropy is defined as the ratio of the equivalent Lambertian flux to the actual flux and is given by (Suttles et al., 1988)

$$
\begin{aligned}
R_{v}(\theta) & =\frac{\pi L_{\mathrm{TOA}}(v, \theta)}{F_{\mathrm{TOA}}(v)}=\frac{L_{\mathrm{TOA}}(v, \theta)}{2 \int_{0}^{\pi / 2} L_{\mathrm{TOA}}(v, \theta) \cos \theta \sin \theta \mathrm{d} \theta} \\
& \approx \frac{L_{\mathrm{TOA}}(v, \theta)}{2\left[\sum_{i=1}^{5} w_{i} L_{\mathrm{TOA}}\left(v, \theta_{i}\right)\right]}
\end{aligned}
$$

where $L_{\mathrm{TOA}}$ is the radiance observed with a viewing angle $\theta$ and $F_{\mathrm{TOA}}$ is the angular integrated flux over a hemisphere, both depending on $v$. In the last step, the five-node GQ was applied. The anisotropy ratio is frequently used in climaterelated studies (Clerbaux et al., 2002; Worden et al., 2011). The equation above implies that knowledge of the anisotropy and the radiance in just one direction allows evaluating the total flux. The anisotropy can be calculated when all relevant surface and atmospheric parameters are known, by simulating spectra over the different GQ angles (see Table 1).

The anisotropy is strongly dependent on cloud coverage, time of day (day or night), surface type and temperature, temperature lapse rate and water vapor columnar content (Suttles et al., 1988; Loeb et al., 2003). It has been previously used in broadband radiometers such as the Earth Radiation Budget Experiment (ERBE) and the Clouds and Earth's Radiant Energy System (CERES) (e.g., Stubenrauch et al.,
1994; Li, 1996; Loeb et al., 2003). The choice of using an anisotropy approximation for performing the angular integration in Eq. (1) was also recently made by Worden et al. (2011) to calculate the $\mathrm{O}_{3}$ IRKs from Aura-TES data.

For small viewing angles, the anisotropy is always larger than 1 throughout the whole spectral range, gradually decreases to 1 as the angle approaches $41^{\circ}$, and drops below 1 when the angle becomes larger than $41^{\circ}$. Using less than five nodes leads to a small positive bias of around $2 \%$, whereas using more than five nodes does not improve the results significantly in terms of accuracy. So while Worden et al. (2011) used the one-node GQ, here we use the five-node approximation to avoid any biases that might be introduced in this stage.

Once the anisotropy has been obtained, the flux can be calculated using Eq. (4) as $F_{v}=\pi L_{v}(\theta) / R_{v}(\theta)$ and the IRK as

$$
\begin{aligned}
\frac{\partial F_{\mathrm{TOA}}}{\partial q\left(z_{l}\right)} & =\frac{\partial}{\partial q\left(z_{l}\right)} \int_{v_{1}}^{v_{2}} \frac{\pi L_{\mathrm{TOA}}(v, \theta)}{R(v, \theta)} \mathrm{d} v \\
& \approx \int_{v_{1}}^{v_{2}} \frac{\partial L_{\mathrm{TOA}}(v, \theta)}{\partial q\left(z_{l}\right)} \frac{\pi \mathrm{d} v}{R(v, \theta)},
\end{aligned}
$$

where in the last step anisotropy was assumed constant with respect to $q\left(z_{l}\right)$. So while the ozone dependence is taken into account in the Jacobian, it is assumed not to play a major role for the anisotropy itself. However, as we will demonstrate in Sect. 4.5, this leads in general to significant errors in the computation of the TOA fluxes.

Example IRKs calculated by Eq. (5) are given in Fig. 2 with red lines. These correspond to IRKs averaged per $10^{\circ}$ viewing angle bins with respect to nadir for 1 day: 15 April 2011.

\subsection{Direct integration of Jacobians}

For this work with IASI we have developed an approach which avoids the main approximation of the anisotropy method. Our method will be referred to as direct integration for the sake of convenience. The direct integration method is based on the direct application of the Gaussian quadrature to the definition of the IRK (Eq. 2). In the anisotropy method the Gaussian quadrature is applied on the radiances $L_{\mathrm{TOA}}$, whereas in the direct integration approach it is applied to the Jacobians $\partial L_{\mathrm{TOA}}(v, \theta, \phi) / \partial q\left(z_{l}\right)$. The IRKs are now calculated as

$$
\frac{\partial F_{\mathrm{TOA}}}{\partial q\left(z_{l}\right)}=2 \pi \sum_{i=1}^{5} w_{i} \int_{v_{1}}^{v_{2}} \frac{\partial L_{\mathrm{TOA}}\left(v, \theta_{i}\right)}{\partial q\left(z_{l}\right)} \mathrm{d} v,
$$

where again $v_{1}=985 \mathrm{~cm}^{-1}$ and $v_{2}=1080 \mathrm{~cm}^{-1}$. For the selection of these angles we follow the five-node GQ, as for the anisotropy, but the $f\left(x_{i}\right)$ function in Eq. (3) does not refer anymore to the radiances, but to the Jacobians. 

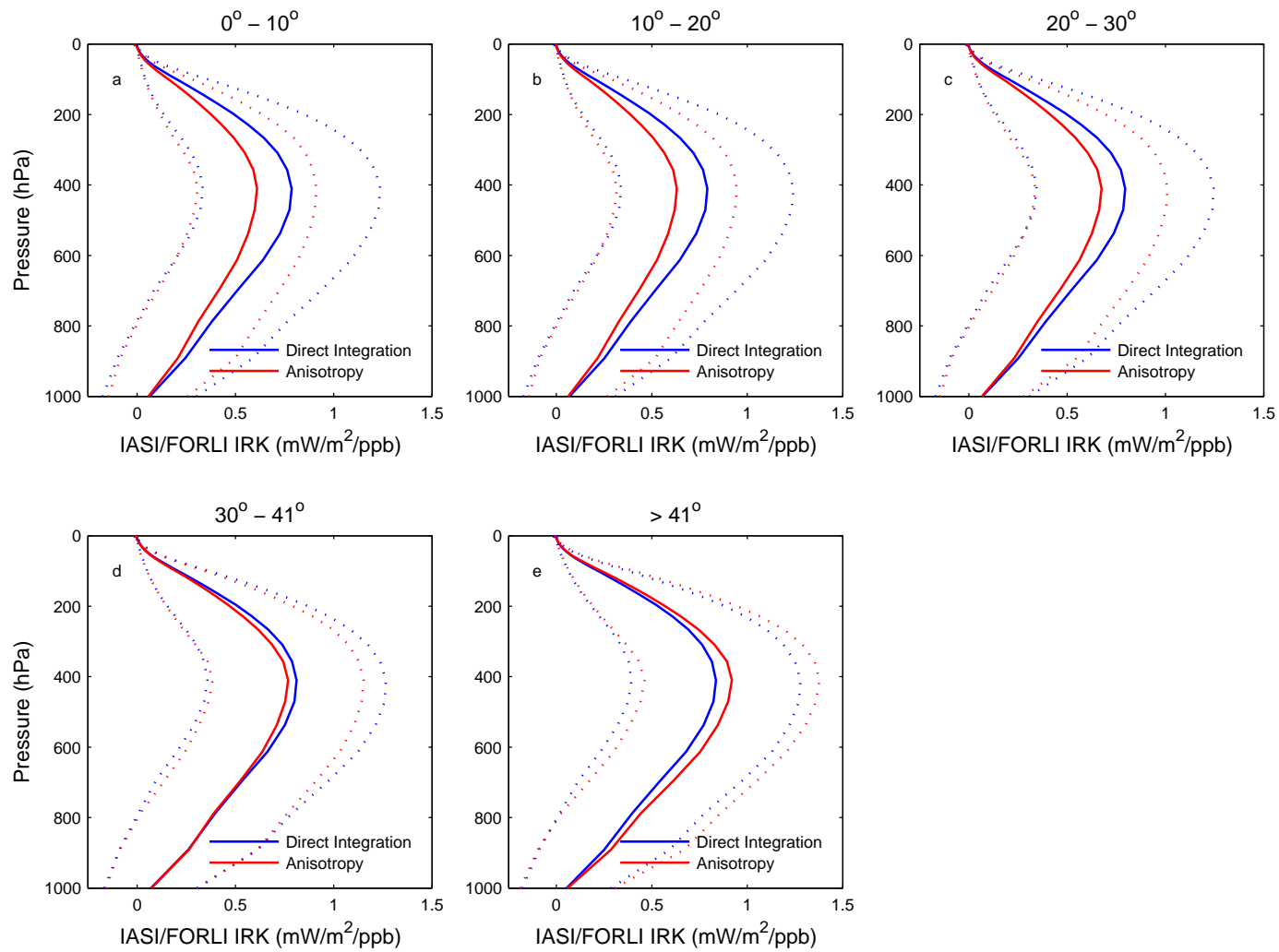

Figure 2. Global average clear-sky ozone IRK profiles as computed via the anisotropy approximation (red line) and the direct integration (blue line) on 15 April 2011. The dashed lines indicate $\pm 1 \sigma$ standard deviations with the same color index. The averages were calculated in bins of $10^{\circ}$ of nadir viewing angle, from 0 to $30^{\circ}$ (a-c), 30 to $41^{\circ}$ (d) and for angles larger than $41^{\circ}$ to maximum $48.3^{\circ}$ (e) for IASI.

Using the angles given in Table 1, we compute with the forward model of FORLI the spectra and Jacobians of Eq. (6) for each IASI measurement, based on the ozone vertical profile, spectrum and other parameters obtained at the last iteration of the retrieval process. Each set of Jacobians is weighted by the proper factor, $w_{i}$, and integrated over the spectral band, with resulting units of $\mathrm{W} \mathrm{m}^{-2} \mathrm{ppb}^{-1}$. The IRK of each layer is then calculated and stored. IRKs calculated with this method are given in Fig. 2 (blue lines), where they are compared to those calculated by using the anisotropy method.

\subsection{IRK comparison}

Applying the chain rule on the second term in Eq. (5), but this time assuming $R$ is a function of the ozone abundance, we get

$$
\begin{aligned}
\frac{\partial F_{\mathrm{TOA}}}{\partial q\left(z_{l}\right)} & =\int_{v_{1}}^{v_{2}} \frac{\partial L_{\mathrm{TOA}}(v, \theta)}{\partial q\left(z_{l}\right)} \frac{\pi \mathrm{d} v}{R(\theta, v)} \\
& -\int_{v_{1}}^{v_{2}} F_{\mathrm{TOA}}(v) \frac{\partial}{\partial q\left(z_{l}\right)} \ln \left(R\left(\theta, v, q\left(z_{l}\right)\right)\right) \mathrm{d} v .
\end{aligned}
$$

The first term on the left-hand side of Eq. (7) is the IRK in the anisotropy approximation. The second term quantifies the difference between the direct integration method and the anisotropy method. Note that calculating this extra term is computationally expensive and application of the chain rule is therefore best avoided by direct integration. The magnitude of this extra term can be assessed by comparing the IRKs of both methods, as in Fig. 2.

Figure 2 shows the average IRKs of a single day, 15 April 2011, as computed by both the direct integration method (blue lines) and the anisotropy approximation (red lines). The average is performed on the global distribution of ozone profiles, considering bins of $10^{\circ}$ from nadir. The last bin goes up to $48.3^{\circ}$, the maximum angle of the IASI viewing swath. Following Worden et al. (2011), IRKs are plotted under the convention that the reduction of TOA flux corresponds to positive forcing; therefore we present the results as positive quantities. The IRKs peak for both methods around the mid-troposphere, which is consistent with the findings of previous studies (Lacis et al., 1990; Worden et al., 2011). The maximum sensitivity for the direct integration method is $0.80 \pm 0.02 \mathrm{~mW} \mathrm{~m}^{-2} \mathrm{ppb}^{-1}$ on average for all bins, and it is found at $8 \mathrm{~km}$ altitude. An important result of Fig. 2 is that the anisotropy approximation underes- 
timates the IRKs by about $22 \%$ at the maximum sensitivity for the bins of 0 to $10^{\circ}$ (Fig. 2a) compared to the direct integration results. The difference decreases as the viewing angle increases (Fig. 2b and c) and tends to zero when the angle approaches $41^{\circ}$ (Fig. 2d). Interestingly, the angle of $41^{\circ}$ is also the result of the one-node GQ for the anisotropy approximation. For viewing angles larger than $41^{\circ}$ (Fig. 2e), the anisotropy approximation overestimates the IRKs compared to the direct integration by $10 \%$ at the maximum sensitivity altitude. The fact that the second term on the left-hand side of Eq. (7) depends on the observation angle through the logarithm of $R$ explains the change from underestimation to overestimation as the viewing angle increases from 0 to $48^{\circ}$. It is worth stressing that IASI has most of its measurements between 0 and $41^{\circ}$, which means that on the global scale the anisotropy method would create a significant underestimation of the IRKs. In integrated layer amounts the anisotropy method exhibits an underestimation of about $20 \%$ in the troposphere and $25 \%$ in total for viewing angles of 0 to $10^{\circ}$, and an overestimation of about 10 and $12 \%$ for the troposphere and total, respectively, for angles larger than $41^{\circ}$.

The estimated errors for the IRKs for the two methods presented above are mainly associated with the retrieval of the ozone profile itself, as presented in Sect. 3. The contribution of the forward model errors is generally small and already accounted for in the retrieved $\mathrm{O}_{3}$ profile error.

\section{Longwave radiative effect}

The IRK defined by Eq. (2) refers to the TOA flux sensitivity to a change in the vertical distribution of ozone and is thus characterizing a single observation. For a specific location and time $i$, we can apply the IRK to an associated difference in ozone abundance, e.g., the difference between a model (sim) and an observation (ref), as

$\Delta_{\mathrm{LWRE}}=\frac{\partial F_{\mathrm{TOA}}^{i}}{\partial q_{i}\left(z_{l}\right)}\left[q_{i}^{\mathrm{sim}}\left(z_{l}\right)-q_{i}^{\mathrm{ref}}\left(z_{l}\right)\right]$,

where $\Delta_{\text {LWRE }}$ (in $\mathrm{W} \mathrm{m}^{-2}$ ) is the difference of the TOA LWRE due to a difference in the ozone amount. Such a difference can be used for instance to assess the results of chemistry-climate models vs. satellite-derived results. This concept was used by Aghedo et al. (2011) to compute the TES ozone IRKs and LWRE and study model-toobservation biases in the vertical and latitudinal distribution of these quantities with four different chemistry-climate models for 1 month. They found for tropical and midlatitude regions significant biases between -0.4 and $+0.7 \mathrm{~W} \mathrm{~m}^{-2}$ for the tropospheric $\mathrm{O}_{3}$ LWRE, when TES had LWRE values around $0.65 \mathrm{~W} \mathrm{~m}^{-2}$ for the same regions. Likewise, Bowman et al. (2013) studied the biases between TES and the chemistry-climate models participating in ACCMIP, even for the seasonal variations of ozone. In their results, the biases in ozone in individual atmospheric layers were small, slightly negative for the Southern ( $\mathrm{SH}$ ) and positive for the Northern Hemisphere (NH), but they accumulated to considerable biases in terms of LWRE. The LWRE biases were found between -0.13 and $+0.2 \mathrm{~W} \mathrm{~m}^{-2}$ for different models and regions. Zonally integrated biases in the ACCMIP ensemble exceeded $0.1 \mathrm{~W} \mathrm{~m}^{-2}$, with individual models exceeding $0.3 \mathrm{~W} \mathrm{~m}^{-2}$. The ACCMIP model ensemble bias was at $0.12 \mathrm{~W} \mathrm{~m}^{-2}$ locally, while the LWRE of TES was around $0.5 \mathrm{~W} \mathrm{~m}^{-2}$ for the same region. These biases were reduced to $39 \pm 41 \mathrm{~mW} \mathrm{~m}^{-2}$ on a global scale due to zonally compensating errors. These OLR biases were correlated with the ACCMIP model-based RF. Based upon this correlation, the intermodel spread was reduced by $30 \%$ in IPCC AR5 (Myhre et al., 2013). It is important to point out, however, that the TES IRKs and LWRE in both studies were computed using the anisotropy approximation. Based upon the direct integration method, the OLR biases from those studies are likely underestimated.

From Eq. (8), if we assume a reference of zero, we can use the retrieved ozone profile, accompanied by its own IRK, to compute the absolute LWRE (Worden et al., 2011) for ozone as

$\mathrm{LWRE}_{i} \approx \frac{\partial F_{\mathrm{TOA}}^{i}}{\partial q_{i}\left(z_{l}\right)} q_{i}\left(z_{l}\right)$,

which represents the reduction in OLR due to ozone absorption with respect to each atmospheric state at mean altitude $z$ of layer $l$. From Eq. (9) we can calculate the LWRE with respect to the ozone profile in each vertical layer, but we can also calculate LWRE separately for total columns and tropospheric or other subcolumns by simply summing over the appropriate vertical layers.

\subsection{LWRE comparison}

Figure 3 shows the zonal average vertical profiles of LWRE for a single day of IASI measurements (15 April 2011) separated between local morning and evening overpasses. The ozone vertical profiles were retrieved with $\mathrm{FORLI}^{-\mathrm{O}_{3}}$ using the parameters specified in Sect. 3. The top row represents the results with the IRKs computed with the direct integration method (Eq. 6), whereas the second row gives the IRKs calculated with the anisotropy approximation (Eq. 5). All IASI viewing angles are included. The two methods show similar broad patterns with expectedly high LWRE values in the stratosphere, larger in the inter-tropical belt and lower in the polar regions due to higher and lower surface temperatures, respectively. The high LWRE found over the $\mathrm{NH}$ midlatitudes are consistent with the high cooling rates in the stratospheric midlatitudes for this mid-spring period (see Clough and Iacono, 1995). We can also notice high LWRE values in the $\mathrm{NH}$ midlatitude mid-troposphere, which are explained by the combined effect of enhanced ozone, due to late effects of Brewer-Dobson circulation in spring, and warm land, in contrast with the cooler and less polluted $\mathrm{SH}$, which 

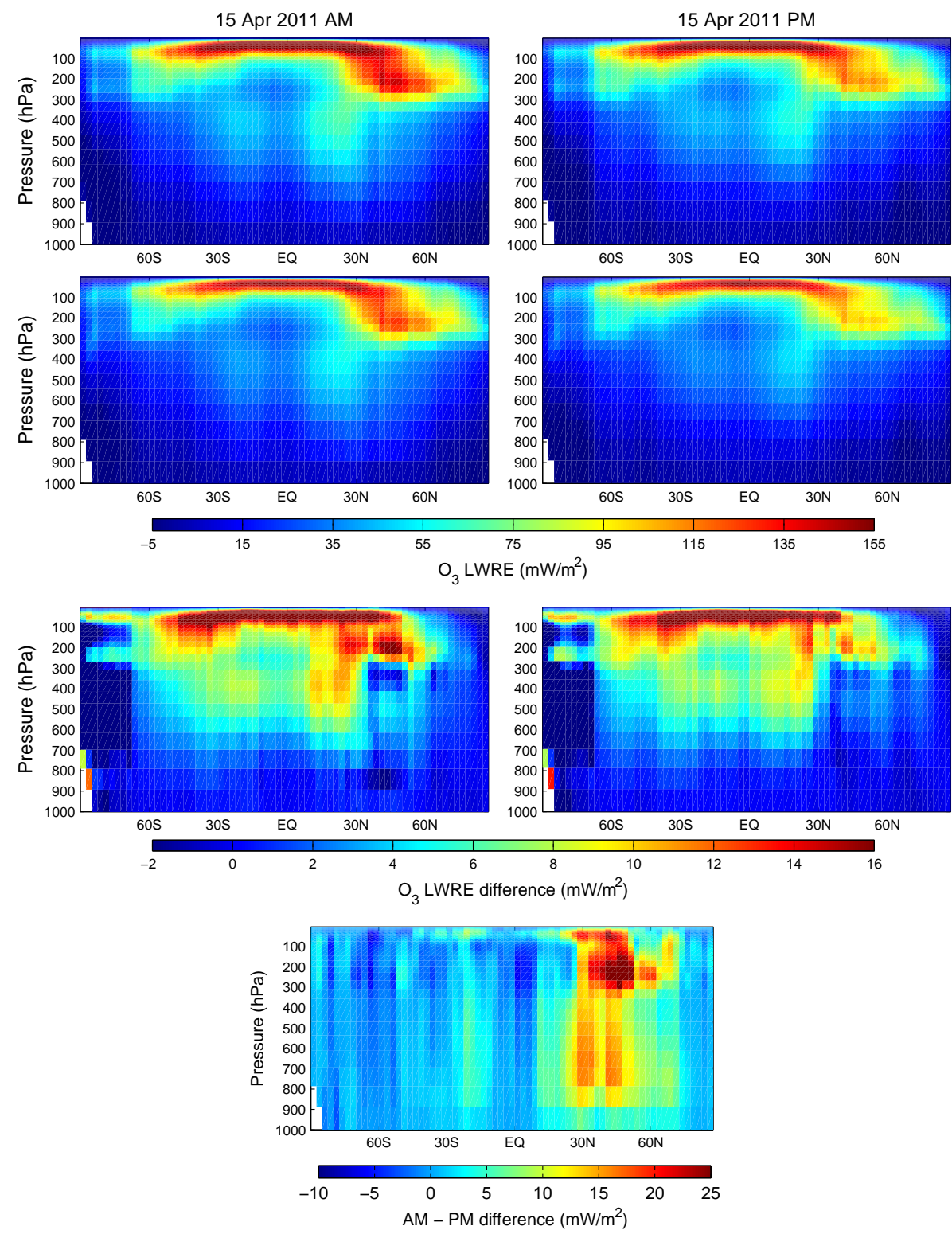

Figure 3. Single-day clear-sky zonal average ozone LWRE profiles for local morning (left) and evening (right) IASI overpasses, on 15 April 2011. The top- and second-row panels provide the LWRE calculated using the direct integration method and the anisotropy approximation, respectively. The third row shows the difference between the two methods. The bottom panel gives the difference between day and night view for the direct integration method.

is dominated by ocean. The NH midlatitude regions, mainly mid-tropospheric but also stratospheric, are highly affected by the surface temperature, as can be seen by comparing the morning and evening values of the LWRE in Fig. 3 (bottom panel). Differences in these regions are up to $25 \mathrm{~mW} \mathrm{~m}^{-2}$ near $250 \mathrm{hPa}$ and $15 \mathrm{~mW} \mathrm{~m}^{-2}$ in the mid-troposphere. As will be shown later in Fig. 6, these differences are mostly related to changes in temperature ( $7 \mathrm{~K}$ between morning and evening at midlatitudes) than to changes in the ozone content (4.2 DU difference between morning and evening). However, at this stage it is difficult to quantify with sufficient accuracy the respective contributions of the $\mathrm{O}_{3}$ abundance and the temperature on the LWRE value. Note that inferring the diurnal change in the LWRE was not possible with TES, considering the much more limited spatial sampling.

The third row of Fig. 3 shows the difference between the LWRE from the direct integration method and the anisotropy approximation. We see significant differences over the entire profile, with absolute differences following the distribution of the LWRE, with a maximum of $16 \mathrm{~mW} \mathrm{~m}^{-2}$ in the stratosphere. In the mid-troposphere the differences are about 6$7 \mathrm{~mW} \mathrm{~m}^{-2}$ in the inter-tropical region, decreasing to almost 

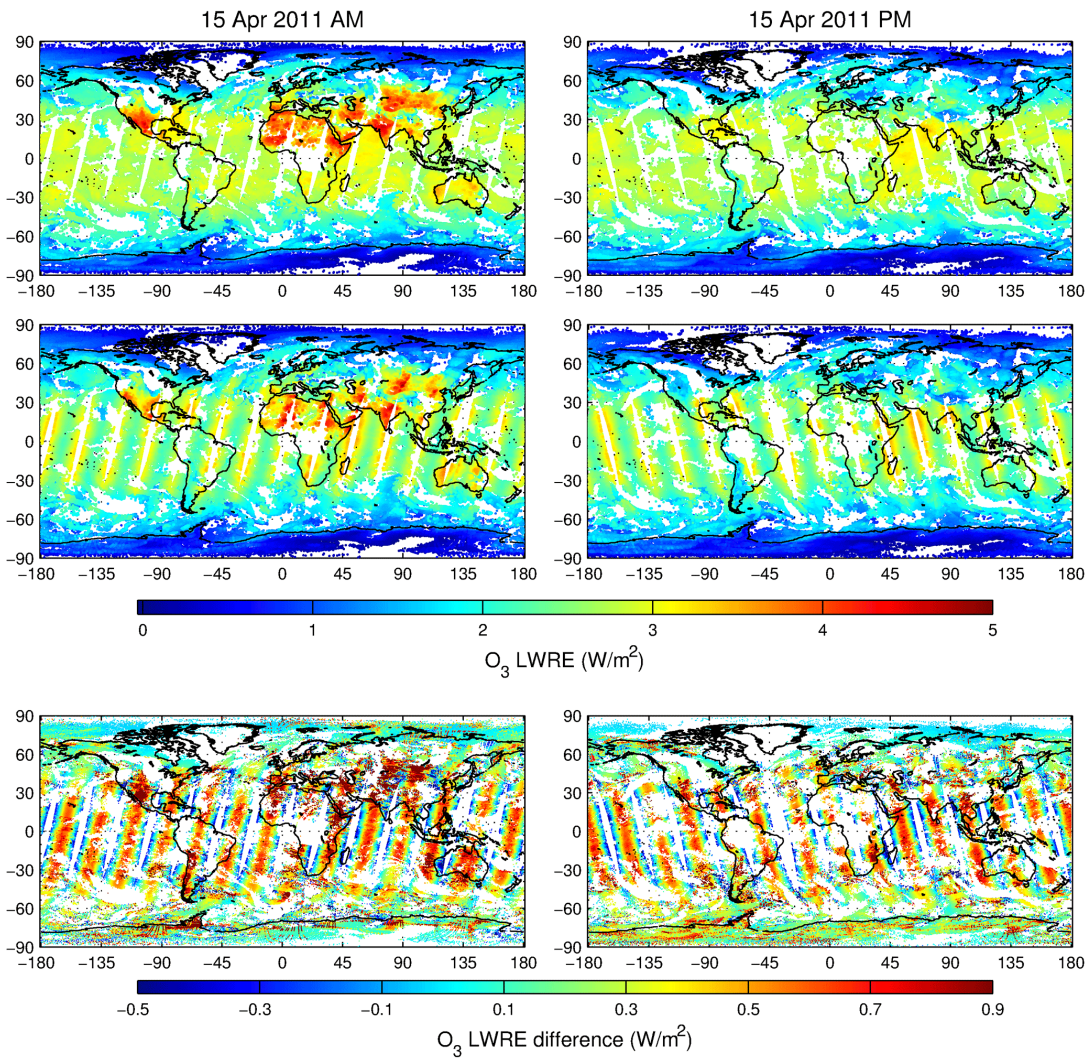

Figure 4. Global distribution of the total $\mathrm{O}_{3}$ LWRE for morning (left) and evening (right) overpasses of IASI, on 15 April 2011. (top) Calculation using the direct integration method, (middle) calculation using the anisotropy approximation and (bottom) the difference between the two methods.

zero at the higher latitudes, where the LWRE itself is almost vanishing. Overall we see an underestimation of the LWRE at all altitudes for the anisotropy method, which is consistent with the IRK comparison (Fig. 2) and the fact that the majority of the IASI measurements are made at angles between 0 and $41^{\circ}$ (corresponding to the negative bias of the anisotropy approximation for the IRKs).

The difference in the LWRE between the two methods is obvious also when comparing the total or tropospheric $\mathrm{O}_{3}$ LWRE values spatially, as shown in Figs. 4 and 5, respectively. As for the zonal averages in Fig. 3, the general patterns are similar between the two methods, with the highest values of the LWRE in the inter-tropical belt and over several continental regions of the $\mathrm{NH}$, logically related to the higher surface temperatures. This effect is more enhanced on the tropospheric LWRE (Fig. 5) than on the total (Fig. 4). Despite this qualitative agreement, the angle-dependent bias of the anisotropy method is obvious in the bottom panels of Figs. 4 and 5: the anisotropy approximation is biased low over most of the IASI swath (red to light-blue colors in the bottom panels) and biased high (blue colors only) at the edges of the swath. The bottom panels of Figs. 4 and 5 correspond to the second term of the right-hand side of Eq. (7), integrated over all (total) and tropospheric layers, respectively. The negative bias of the anisotropy approximation for the LWRE is larger at near nadir and reaches almost $1 \mathrm{~W} \mathrm{~m}^{-2}(25 \%)$ on the total LWRE and around $0.4 \mathrm{~W} \mathrm{~m}^{-2}(25 \%)$ on the tropospheric LWRE. The positive bias is smaller, around $20 \%$, for both total and tropospheric LWRE $\left(0.5\right.$ and $0.2 \mathrm{Wm}^{-2}$, respectively) due to the fact that both methods tend to agree at a viewing angle of $41^{\circ}$. Note that in the polar regions the effect is not seen, but this is due to the compensation of positive and negative biases for overlapping orbits and the very low values of LWRE. Finally the differences between morning and evening overpasses of Fig. 4 top panels, where the hotspots appearing at the morning view disappear during the evening view, reinforces the assumption that the differences in the LWRE vertical distribution between morning and evening (Fig. 3, bottom panel) are indeed due to temperature difference. Here we chose to show results only for 15 April 2011, since the pattern of the differences between the two methods is the same for all days, as it is angle related.

To produce an error budget for the LWRE, we account for the following two contributions: that of the forward model, for the part of the IRK formulation, and that of the retrieval, for the profile of $\mathrm{O}_{3}$, based on Eq. (9). A good estimation of the forward model errors is the rms value of the spec- 

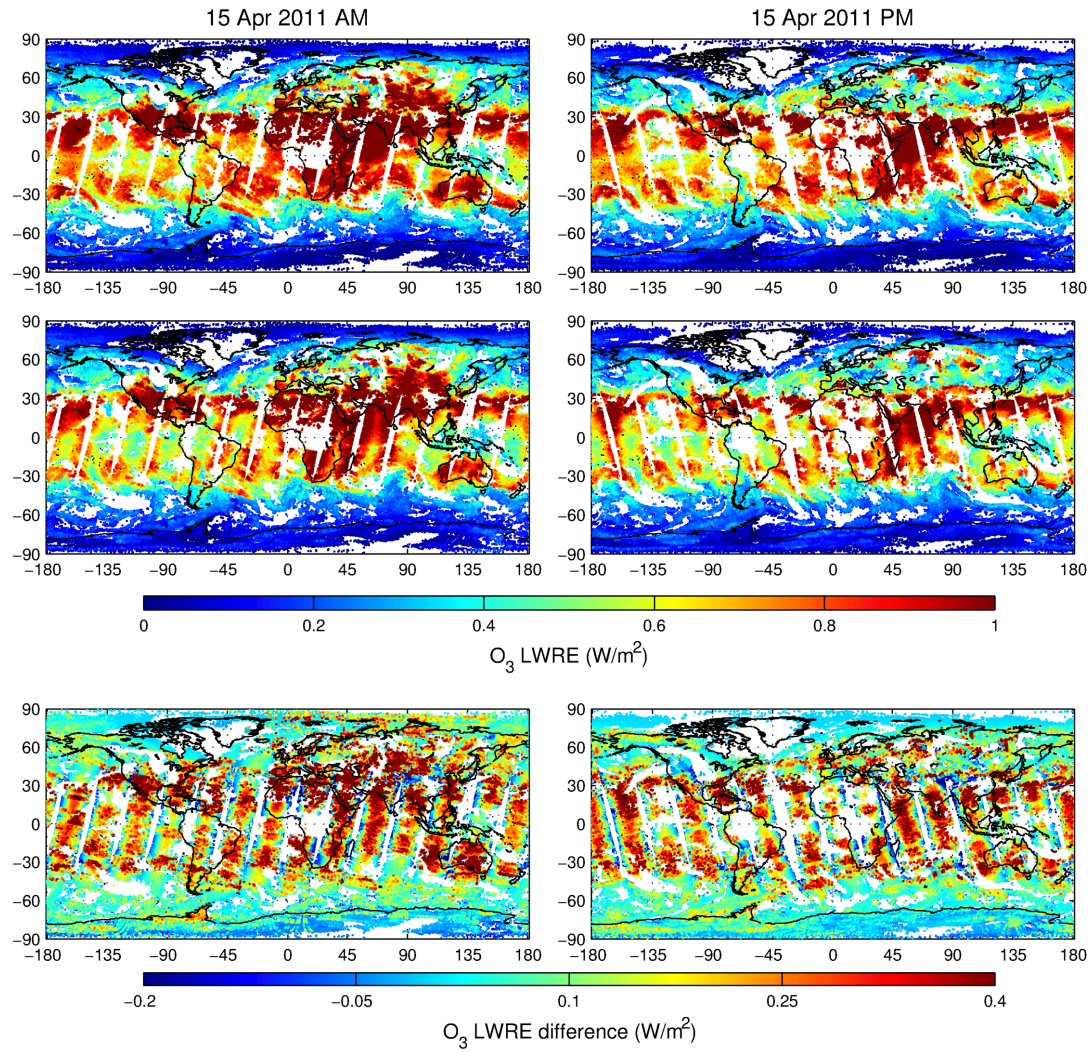

Figure 5. Same as Fig. 4 but for the tropospheric $\mathrm{O}_{3}$ LWRE. The calculation of the tropospheric LWRE relies on the definition of the tropopause by the WMO (1957).

tral residual between the observed and the modeled spectrum. The LWRE, as the product of Eq. (9), refers to a column of ozone. For the integrated total LWRE, the contribution of the retrieval is very small, and therefore we consider only the rms to account for all errors. A typical rms for good quality ozone retrievals with FORLI is around $2.24 \times 10^{-8} \mathrm{~W} \mathrm{~cm}^{-2} \mathrm{sr}^{-1} \mathrm{~cm}$, which translates for the total LWRE global average to a $\pm 3.2 \%$ error. In some cases the rms can be larger, but the data are not kept when its value is above $3.5 \times 10^{-8} \mathrm{~W} \mathrm{~cm}^{-2} \mathrm{sr}^{-1} \mathrm{~cm}$, which places an upper bound of $\pm 4.6 \%$ on the LWRE error.

\subsection{LWRE annual variation}

As already mentioned in the Introduction, the ozone radiative forcing is dependent not only on the local ozone profile but also on the surface temperature, the atmospheric temperature profile and the humidity profile.

Figure 6 shows the seasonality of both tropospheric and total $\mathrm{O}_{3}$ LWRE, based on the direct integration method. Due to the computational resources the data were obtained globally, albeit only for a single day per month: the 15th of each month for the year 2011 (note that for November and December 2011, the 16th was selected, as for the 15th the IASI spatial coverage was not global). The results will therefore be affected by the single-day atmospheric conditions, which might not be representative of the whole month, but this is expected to be minimized by the fact that we look at latitudinal averages, in which typically around 45000 data points are included. Moreover we recall that only cloud-free measurements are processed, which will cause biases in the distributions and time series in comparison to what would correspond to (real) all-sky conditions, as discussed in Worden et al. (2011). More specifically Figs. 6, 7 and 8 show the monthly variability of the $\mathrm{O}_{3}$ LWRE, the surface temperature and the $\mathrm{O}_{3}$ columnar amount, separately for polar regions $\left(60-90^{\circ} \mathrm{N}\right.$ and $\left.60-90^{\circ} \mathrm{S}\right)$, midlatitudes $\left(30-60^{\circ} \mathrm{N}\right.$ and $\left.30-60^{\circ} \mathrm{S}\right)$ and tropical regions $\left(30^{\circ} \mathrm{N}-30^{\circ} \mathrm{S}\right)$. The time series are also separated between local day and night, marked with red and blue lines, respectively. Note that the average values are area-weighted to avoid as much as possible biases due to varying sampling as a function of region. The area weighting is achieved as follows: we first sort all IASI measurements based on latitude and longitude in a $1^{\circ} \times 1^{\circ}$ grid. We then calculate the mean LWRE of all LWRE values that hit each grid cell (LWRE ${ }_{i}^{\text {mean }}$ ), as well as the area of each grid cell in square kilometers $\left(W_{i}\right)$. Not all grid cells end up filled necessarily. For each area of interest we calculate the area-weighted LWRE average by 


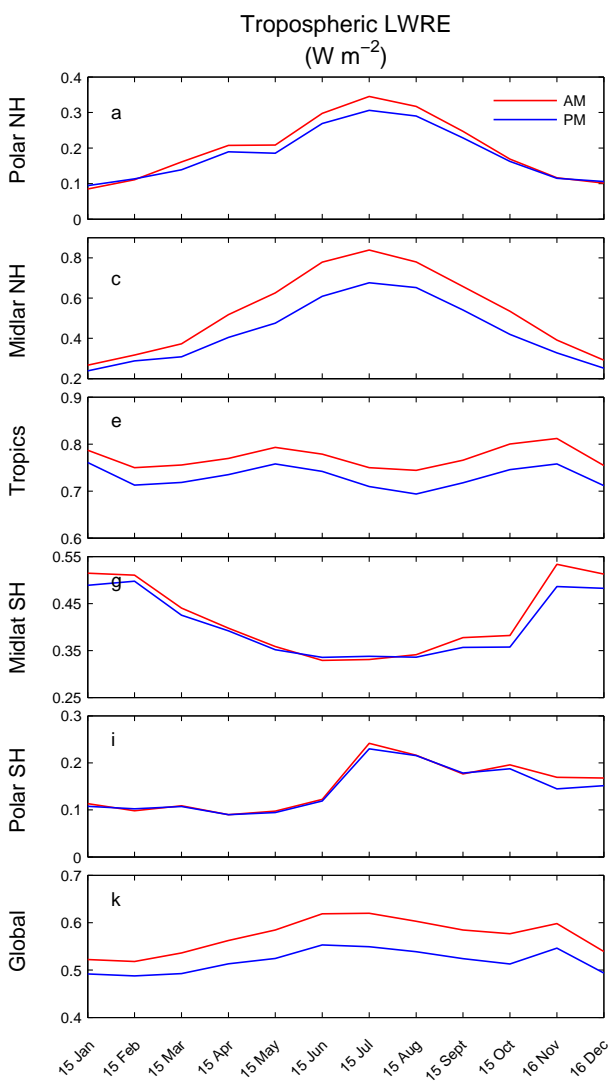

2011

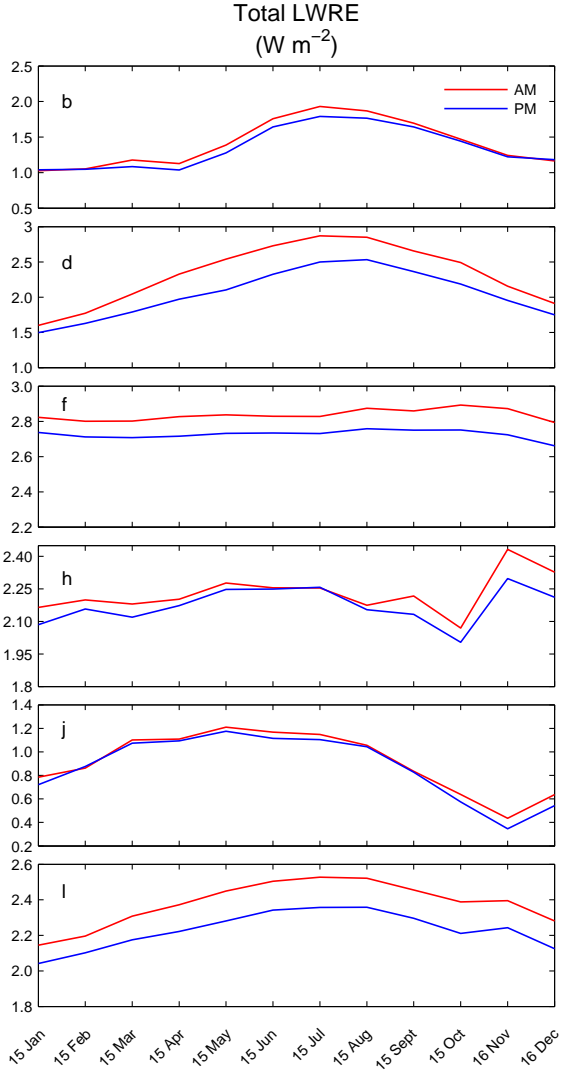

2011

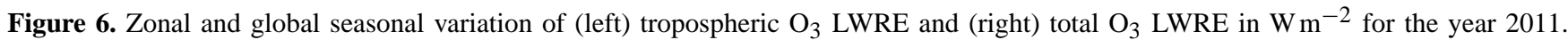
Panels (a, b) and (c, d) refer to Northern Hemisphere polar and midlatitude regions, respectively; panels (e) and (f) represent the tropics; panels $(\mathbf{g}, \mathbf{h})$ and $(\mathbf{i}, \mathbf{j})$ refer to SH midlatitudes and polar regions, respectively. Panels $(\mathbf{k}, \mathbf{l})$ refer to global averages.

$\langle\mathrm{LWRE}\rangle=\frac{\sum_{i} \mathrm{LWRE}_{i}^{\mathrm{mean}} \times W_{i}}{\sum_{i} W_{i}}$.

Note also the different scales in the $y$ axes between tropospheric and total LWRE of the same zone, as well as between different zones for the same quantity. The analysis of Fig. 6 reveals the following main patterns:

a. The $\mathrm{O}_{3}$ LWRE is consistently larger for the IASI morning measurements. The morning-evening differences are not seen in the SH polar region and midlatitudes but do appear clearly for the three other latitudinal bands, reaching around 0.16 and $0.38 \mathrm{Wm}^{-2}$ at $\mathrm{NH}$ midlatitudes during spring and summer for the tropospheric and total LWRE, respectively. As seen in Fig. 7, and in the morning-evening differences of both tropospheric and total $\mathrm{O}_{3}$ columns in Fig. 8, these variations are not related to changing ozone but to changes in temperatures, which reach almost $7 \mathrm{~K}$ during spring and summer for the same region. The larger impact at the northern latitudes (and conversely the absence of impact between 30 and $90^{\circ} \mathrm{S}$ ) is therefore explainable by the importance of the continental areas. Note that it is the first time that the diurnal variability in the LWRE is characterized empirically on such large scales.

b. The LWRE in the NH polar region (Fig. 6a and b) is characterized by low values for the beginning of the year, with a maximum in July, and gradually falls back to low values towards the end of the year, which is consistent with the surface temperature variation (Fig. 7a). The relative amplitude of the seasonal cycle is similar between tropospheric and total LWRE, around a factor of 3 and a factor of 2, respectively, between extremes. A noticeable feature in Fig. $6 \mathrm{~b}$ is the relatively constant low values of the LWRE in JanuaryApril 2011. This is due to the fact that the beginning of 2011 for the polar NH was characterized by the impact of an unusually prolonged and severe polar vortex, which started at the end of 2010 and finally collapsed 


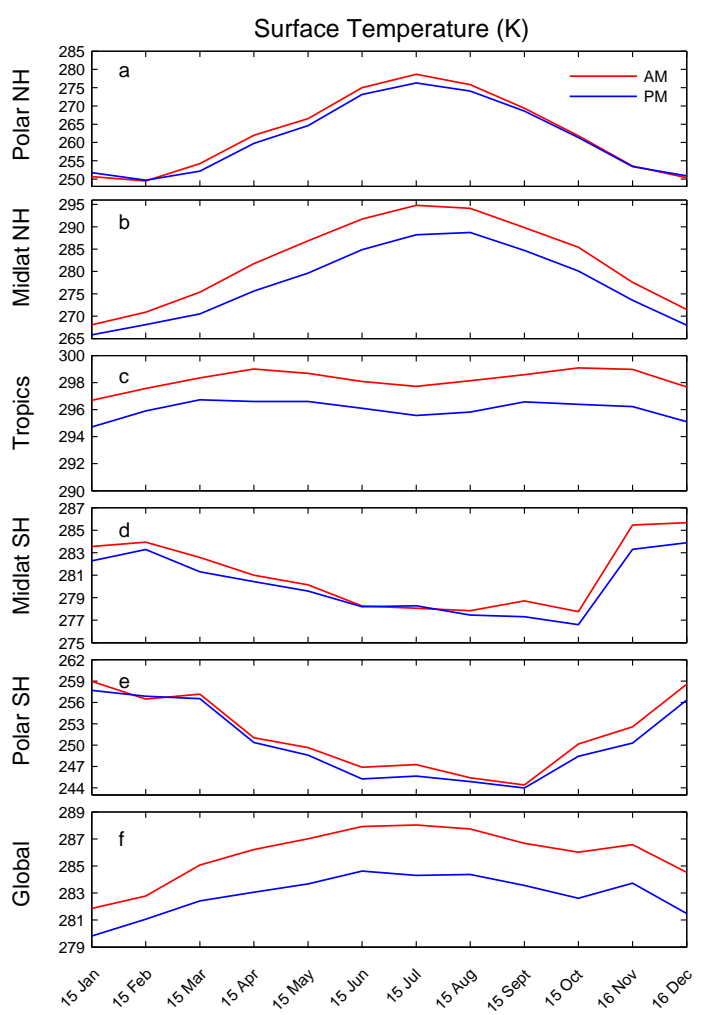

2011

Figure 7. Same as Fig. 6 but for surface temperature in K.

around April 2011, causing a serious depletion of ozone (Manney et al., 2011; Balis et al., 2011). This can also be seen in Fig. $8 b$, where the $\mathrm{O}_{3}$ total column shows a relatively low plateau between January and March and a sudden maximum in April, while in normal conditions we would expect a smoother increase of ozone from January to April. Another feature for the polar NH is the plateau in the LWRE for the tropospheric column (Fig. 6a) between April and May 2011, which could be due to the effect of stratospheric intrusions - as can be seen by the sharp peak in the $\mathrm{O}_{3}$ tropospheric column (Fig. 8a). After July 2011 we see a smooth decrease of the tropospheric LWRE, consistent with the simultaneous decrease of the $\mathrm{O}_{3}$ tropospheric column and the surface temperature. Note that for this region the total LWRE is constantly 5 to 10 times larger compared to the tropospheric LWRE.

c. The midlatitude NH (Fig. 6c and d) is the region where the largest LWREs are calculated, both for tropospheric (around $0.8 \mathrm{~W} \mathrm{~m}^{-2}$ in July during daytime) and total LWRE $\left(2.8 \mathrm{~W} \mathrm{~m}^{-2}\right.$ in daytime in July also). The seasonality in this latitude band is well marked, with minima in winter and maxima during summer, especially on the tropospheric LWRE, with amplitude as large as
$0.6 \mathrm{~W} \mathrm{~m}^{-2}$ (corresponding to an increase of a factor of 3 from winter to summer). This seasonality in the troposphere is related to temperature (see Fig. 7b), as well as to enhanced photochemical production of $\mathrm{O}_{3}$ from precursors in summer (Fig. 8c). As stressed above, the temperature impact is also reflected in the large daynight difference, as for 15 July 2011 a $7 \mathrm{~K}$ difference in the surface temperature causes differences of up to $0.16 \mathrm{~W} \mathrm{~m}^{-2}$ for the tropospheric and $0.38 \mathrm{~W} \mathrm{~m}^{-2}$ for the total LWRE, while the difference in the $\mathrm{O}_{3}$ amount between day and night is negligible for both columns.

d. The tropical total $\mathrm{O}_{3}$ LWRE (Fig. 6f) shows little variation over the months. The relatively high values of LWRE (around $2.8 \mathrm{~W} \mathrm{~m}^{-2}$ ) for this low- $\mathrm{O}_{3}$ region are due to the high temperatures (Fig. 7c). The small increase observed between July and October is due to an increase in ozone as seen in Fig. 8f, which, following previous research, would be mainly in the lower stratosphere (Stolarski et al., 2014). The tropospheric LWRE (Fig. 6e) in the tropics shows more variability with the seasonal cycle characterized by a double maximum in May and October-November. These maxima are consistent with the maxima of the $\mathrm{O}_{3}$ tropospheric column in Fig. 8e, which are associated with transport of ozonerich air masses following enhanced biomass burning (Galanter et al., 2000; Ziemke et al., 2009) and lightning periods (Martin et al., 2000; Sauvage et al., 2007; Ziemke et al., 2011), especially for the SH tropics.

e. Moving to the SH, at midlatitudes, the total LWRE (Fig. 6h) is characterized by a relatively weak variability $\left(2.2 \pm 0.2 \mathrm{~W} \mathrm{~m}^{-2}\right)$, apart from a small decrease after July, which is likely associated with the expansion of the Antarctic polar vortex area and its low temperatures towards southern midlatitudes. The minimum value in October is consistent with the surface temperature minimum (Fig. 7d), while the $\mathrm{O}_{3}$ total column (Fig. 8h) reaches its maximum value around the same time $(\mathrm{SH}$ spring). The high values in November-December 2011 follow the pattern of the surface temperature as we enter the SH summer. The seasonality is more pronounced for the tropospheric LWRE at southern midlatitudes (Fig. 6g), with maxima between October and February (relatively constant at $0.5 \mathrm{~W} \mathrm{~m}^{-2}$ ) and minima in $\mathrm{SH}$ winter, which may be associated with the corresponding seasonality of the surface temperature (Fig. 7d) and the $\mathrm{O}_{3}$ tropospheric columns (Fig. 8g). Note that the maximum tropospheric LWRE of the SH is almost twice as low as that in the $\mathrm{NH}$ (Fig. 6c), which is consistent with the lower ozone content of the region (Fig. $8 \mathrm{~g}$ and $\mathrm{h}$ compared to Fig. $8 \mathrm{c}$ and d).

f. For the polar regions of the SH, the total LWRE (Fig. 6j) shows a seasonality that closely follows the ozone total column variation (Fig. 8j). The impact of the Antarc- 

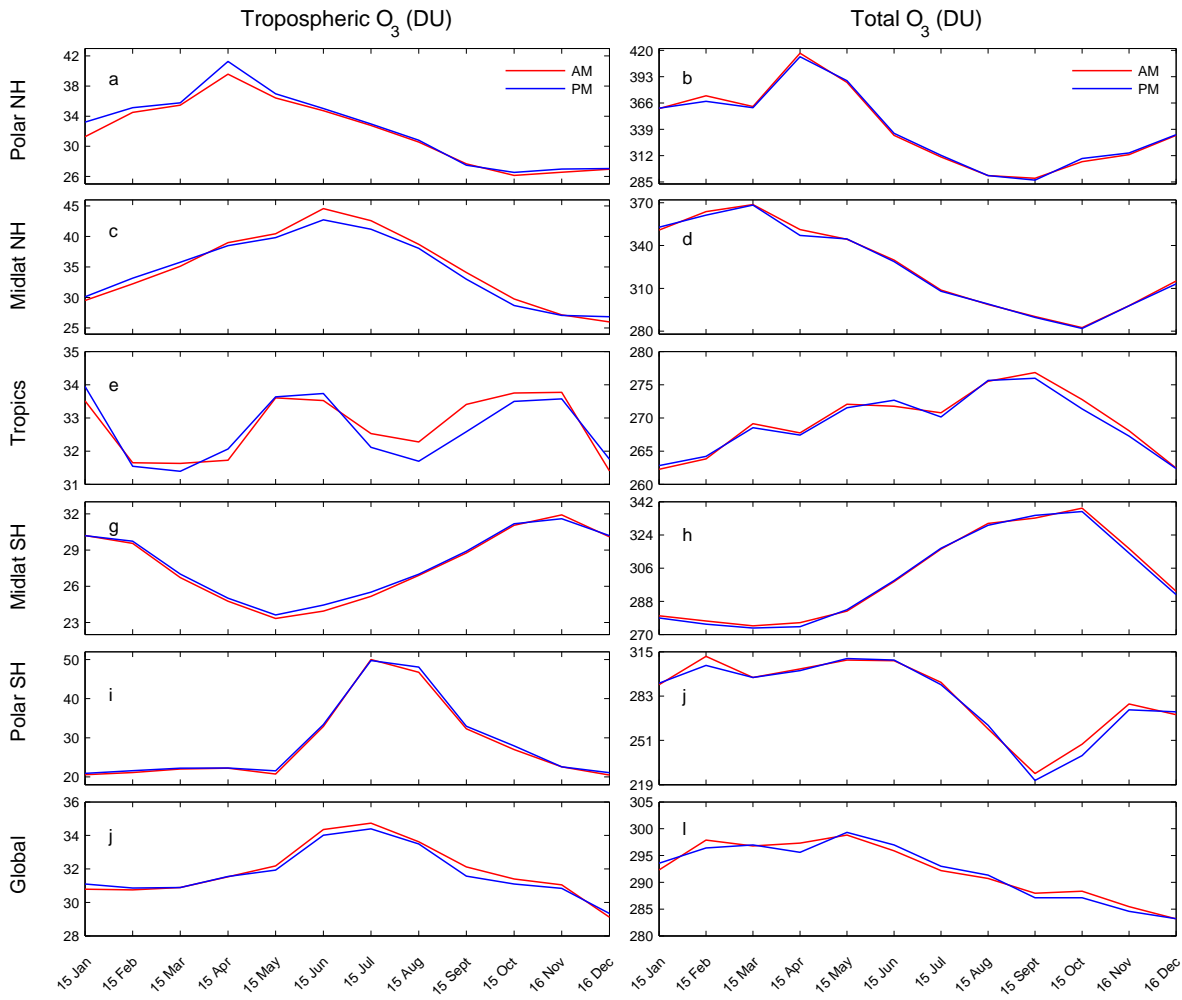

2011

2011

Figure 8. Same as Fig. 6 but for tropospheric and total columns of $\mathrm{O}_{3}$ in DU.

tic polar vortex is well seen, starting to build up in May, reaching its maximum covered area in September to the first half of November (NOAA ESRL/GMD, 2015) and completely collapsing in December. The $\mathrm{O}_{3}$ in the vortex decreases following catalytic destruction in winter/spring, reaching its minimum column in September 2011 (Fig. 8j); this explains the rapid decrease after August 2011 of the total LWRE, reaching also its lowest value in October-November 2011. The temperature has a weaker impact on the seasonality in this polar region, as can be seen also from the absence of day-night differences. Note that the SH polar LWRE maximum barely reaches $1.2 \mathrm{~W} \mathrm{~m}^{-2}$ compared to the $2 \mathrm{~W} \mathrm{~m}^{-2}$ maximum found in the $\mathrm{NH}$ polar region. The tropospheric $\mathrm{O}_{3}$ LWRE (Fig. 6i) is characterized by a very different seasonality than the total LWRE with a rapid increase from June to July, which is consistent with the increase of $\mathrm{O}_{3}$ tropospheric column (Fig. 8i) for the same period, possibly caused by stratospheric intrusions. Higher tropospheric $\mathrm{O}_{3}$ values are also reported in NOAA ESRL/GMD (2015) for the same period of 2011. After the peak, from August and thereafter, the tropospheric LWRE follows a progressive decrease, which is much slower than the decrease of the $\mathrm{O}_{3}$ tropospheric column. This slower decrease is ex- plained again by the competing effects of ozone and temperature, with the temperature (Fig. 7e) compensating here for the decreases in tropospheric $\mathrm{O}_{3}$.

g. Finally, global averages of both tropospheric and total $\mathrm{O}_{3}$ LWRE (Fig. 6k and 1) show little variation throughout the year, as the effects of the one hemisphere appear to almost counterbalance the effects of the other. Nonetheless the impact of the $\mathrm{NH}$ is quite evident, as both global averages exhibit a moderate peak in July, following the $\mathrm{NH}$ polar and midlatitude patterns. This is also supported by the $\mathrm{O}_{3}$ global average tropospheric and total columns (Fig. 8k and 1), which follow the same annual variation as the $\mathrm{NH}-$ mostly midlatitude $-\mathrm{O}_{3}$ columns. These global averages can be compared with other studies. For instance, Worden et al. (2011) calculated with TES a global $\left(80^{\circ} \mathrm{N}-80^{\circ} \mathrm{S}\right)$ average clearsky tropospheric $\mathrm{O}_{3}$ LWRE for August 2006 of $0.50 \pm$ $0.24 \mathrm{~W} \mathrm{~m}^{-2}$, while in this paper for 15 August 2011 we find $0.60 \pm 0.12 \mathrm{~W} \mathrm{~m}^{-2}$ for the morning overpasses and $0.54 \pm 0.08 \mathrm{~W} \mathrm{~m}^{-2}$ for the evening overpasses. It should be kept in mind, however, that our calculations are based on single-day distributions and, more importantly, use the direct integration method, as opposed to the anisotropy method used in Worden et al. (2011). 
A detailed comparison between IASI and TES-derived LWRE will be done in a separate study.

\section{Conclusions}

With the use of the IASI-FORLI-O 3 TOA radiance Jacobians with respect to the ozone vertical distribution, we were able to quantify the sensitivity of the OLR to ozone by calculating the instantaneous radiative kernels for clear-sky scenes. Furthermore we calculated the longwave radiative effect of ozone due to absorption. These calculations were performed using two different methods: the anisotropy approximation, which is a simplified approach with a moderate requirement of computational resources, and the direct integration method, which follows more strictly the application of the IRK definition but demands more computational resources. A step-by-step comparison between the two methods was conducted for both the IRKs and the LWRE, using global daily data from the IASI instrument on the MetOp-A satellite. We have shown that the anisotropy approximation results in biases from -25 to $+12 \%$ on the IRKs, depending on the viewing angle, and -25 to $+20 \%$ for the LWRE. The two methods coincide for the viewing angle of $41^{\circ}$ from nadir, with the anisotropy results being biased low and high for smaller and larger angles, respectively. Regardless of the bias, the anisotropy approximation captures the variability of the LWRE similar to the direct integration method and could be used if accuracy is not a priority. However, for future comparisons with climate models or other thermal IR instruments, these biases need to be avoided and the use of the direct integration method is recommended. The vertical distribution of the LWRE for a single day was also investigated, separately for day and night views. Although both methods show the same global patterns, the anisotropy method substantially underestimates on the global scale the LWRE in the layers of maximum sensitivity, as most IASI viewing angles are between 0 and $41^{\circ}$. The day-night difference in the LWRE was evaluated for the first time, owing to the bi-daily coverage of IASI, and we found a significant role of the temperature in the flux sensitivity, with changes in the LWRE varying from -10 to $25 \mathrm{~mW} \mathrm{~m}^{-2}$ locally between day and night. The larger differences are over the $\mathrm{NH}$ midlatitudes in the UTLS, which corresponds to the maximum in the LWRE itself.

For the first time we were also able to investigate the annual variation of the tropospheric and total $\mathrm{O}_{3}$ LWRE, separately for day and night overpasses of IASI, with respect to changes in surface temperature and ozone abundance. The impact of the surface temperature on the seasonality is clear, especially for the $\mathrm{NH}$ regions, dominated by continents, as well as on the diurnal cycle, with the daytime LWRE being consistently larger at almost all times and almost all latitudes. In addition to surface temperature, changes in ozone affect the seasonality of the LWRE, in some regions differently for the tropospheric and the total amounts (e.g., in the Antarctic, where the ozone hole strongly affects the total LWRE). The seasonality was looked at in different latitude bands, revealing a much stronger LWRE of ozone in the NH (maximum at midlatitudes in summer), where we find larger $\mathrm{O}_{3}$ columns and higher surface temperatures, compared to the $\mathrm{SH}$. This is also evident in the global averages, which mostly follow the NH variations. Overall, the NH LWRE seasonality seems to be mostly driven by the surface temperature, while the $\mathrm{SH}$, especially the polar region, is more influenced by the $\mathrm{O}_{3}$ amount. Further investigation is needed to quantify the respective contribution of temperature and ozone on the LWRE, as these two parameters seem to have a competing effect on its seasonality. The contribution of other parameters, such as humidity in the $9.6 \mu \mathrm{m}$ band, should also be investigated.

Finally, the IRKs and LWRE can also serve to assess and constrain climate model biases in the calculation of the radiative forcing, as was done previously albeit with the use of the anisotropy approximation. However, the direct integration method gives more accurate results and, in cooperation with the high spatiotemporal coverage of IASI instruments, would enforce the capabilities of climate models.

Acknowledgements. IASI was developed and built under the responsibility of the "Centre National d'Etudes Spatiales" (CNES, France). It is flown on board the MetOp satellites as part of the EUMETSAT Polar System. The IASI L1 and L2 data are received through the EUMETCast near-real-time data distribution service. The research in Belgium was funded by the F.R.S.-FNRS; the Belgian State Federal Office for Scientific, Technical and Cultural Affairs; and the European Space Agency (ESA-Prodex arrangements IASI.Flow and BO3M-SAF). We acknowledge support from the $\mathrm{O}_{3}$-CCI project funded by ESA and by the O3M-SAF project funded by EUMETSAT. L. Clarisse and P.-F. Coheur are respectively research associate (Chercheur Qualifié) and senior research associate (Maitre de Recherches) with the Belgian F.R.S.-FNRS. C. Clerbaux is grateful to CNES for scientific collaboration and financial support. K. W. Bowman and H. M. Worden were funded by a NASA-ROSES 2013 Aura Science Team proposal.

Edited by: J.-U. Grooß

\section{References}

Abramowitz, M. and Stegun, I.: Handbook of Mathematical Functions with Formulas, Graphs, and Mathematical Tables, National Bureau of Standards, Applied Mathematics Series - 55, Dover, Mineola, NY, USA, 1972.

Aghedo, A. M., Bowman, K. W., Worden, H. M., Kulawik, S. S., Shindell, D. T., Lamarque, J. F., Faluvegi, G., Parrington, M., Jones, D. B. A., and Rast, S.: The vertical distribution of ozone instantaneous radiative forcing from satellite and chemistry climate models, J. Geophys. Res., 11, D01305, doi:10.1029/2010jd014243, 2011. 
August, T., Klaes, D., Schlüssel, P., Hultberg, T., Crapeau, M., Arriaga, A., O'Carroll, A., Coppens, D., Munro, R., and Calbet, X.: IASI on and Metop-A: operational level 2 retrievals after five years in orbit, J. Quant. Spectrosc. Ra., 113, 1340-1371, doi:10.1029/2010jd014243, 2012.

Balis, D., Isaksen, I. S. A., Zerefos, C., Zyrichidou, I., Eleftheratos, K., Tourpali, K., Bojkov, R., Rognerud, B., Stordal, F., Søvde, O. A., and Orsolini, Y.: Observed and modelled record ozone decline over the Arctic during winter/spring 2011, Geophys. Res. Lett., 3, L23801, doi:10.1029/2011GL049259, 2011.

Bowman, K. W., Steck, T., Worden, H. M., Worden, J., Clough, S., and Rodgers, C.: Capturing time and vertical variability of tropospheric and ozone: a study using TES nadir retrievals, J. Geophys. Res., 107, D23, doi:10.1029/2002JD002150, 2002.

Bowman, K. W., Shindell, D. T., Worden, H. M., Lamarque, J.F., Young, P. J., Stevenson, D. S., Qu, Z., de la Torre, M., Bergmann, D., Cameron-Smith, P. J., Collins, W. J., Doherty, R., Dalsøren, S. B., Faluvegi, G., Folberth, G., Horowitz, L. W., Josse, B. M., Lee, Y. H., MacKenzie, I. A., Myhre, G., Nagashima, T., Naik, V., Plummer, D. A., Rumbold, S. T., Skeie, R. B., Strode, S. A., Sudo, K., Szopa, S., Voulgarakis, A., Zeng, G., Kulawik, S. S., Aghedo, A. M., and Worden, J. R.: Evaluation of ACCMIP outgoing longwave radiation from tropospheric ozone using TES satellite observations, Atmos. Chem. Phys., 13, 4057-4072, doi:10.5194/acp-13-4057-2013, 2013.

Boynard, A., Clerbaux, C., Coheur, P.-F., Hurtmans, D., Turquety, S., George, M., Hadji-Lazaro, J., Keim, C., and MeyerArnek, J.: Measurements of total and tropospheric ozone from IASI: comparison with correlative satellite, ground-based and ozonesonde observations, Atmos. Chem. Phys., 9, 6255-6271, doi:10.5194/acp-9-6255-2009, 2009.

Clarisse, L., R'Honi, Y., Coheur, P.-F., Hurtmans, D., and Clerbaux, C., Thermal infrared nadir observations of 24 atmospheric gases, Geophys. Res. Lett., 3, L10802, doi:10.1029/2011GL047271, 2011.

Clerbaux, N., Dewitte, S., Gonzalez, L., Bertrand, C., Nicula, B., and Ipe, A., Outgoing longwave flux estimation: improvement of angular modelling using spectral information, Remote Sens. Environ., 85, 389-395, doi:10.1016/S0034-4257(03)00015-4, 2002.

Clerbaux, C., Boynard, A., Clarisse, L., George, M., HadjiLazaro, J., Herbin, H., Hurtmans, D., Pommier, M., Razavi, A., Turquety, S., Wespes, C., and Coheur, P.-F.: Monitoring of atmospheric composition using the thermal infrared IASI/MetOp sounder, Atmos. Chem. Phys., 9, 6041-6054, doi:10.5194/acp9-6041-2009, 2009.

Clough, S. A. and Iacono, M. J.: Line-by-line calculation of atmospheric fluxes and cooling rates: 2. Application to carbon dioxide, ozone, methane, nitrous oxide and the halocarbons, J. Geophys. Res., 100, 16519-16535, doi:10.1029/95JD01386, 1995.

Coheur, P.-F., Barret, B., Turquety, S., Hurtmans, D., HadjiLazaro, J., and Clerbaux, C.: Retrieval and characterization of ozone vertical profiles from a thermal infrared nadir sounder, J. Geophys. Res., 110, D24303, doi:10.1029/2005JD005845, 2005.

Coheur, P.-F., Clarisse, L., Turquety, S., Hurtmans, D., and Clerbaux, C.: IASI measurements of reactive trace species in biomass burning plumes, Atmos. Chem. Phys., 9, 5655-5667, doi:10.5194/acp-9-5655-2009, 2009.
Conley, A. J., Lamarque, J.-F., Vitt, F., Collins, W. D., and Kiehl, J.: PORT, a CESM tool for the diagnosis of radiative forcing, Geosci. Model Dev., 6, 469-476, doi:10.5194/gmd-6-469-2013, 2013.

Dufour, G., Eremenko, M., Griesfeller, A., Barret, B., LeFlochmoën, E., Clerbaux, C., Hadji-Lazaro, J., Coheur, P.-F., and Hurtmans, D.: Validation of three different scientific ozone products retrieved from IASI spectra using ozonesondes, Atmos. Meas. Tech., 5, 611-630, doi:10.5194/amt-5-611-2012, 2012.

EUMETSAT: IASI Level 1: Product Guide, EUM/OPSEPS/MAN/04/0032 v4C, available at: http://www.eumetsat. int/website/home/Data/Products/Level1Data/index.html (last access: 3 November 2015), 2014.

Forster, P., Ramaswamy, V., Artaxo, P., Berntsen, T., Betts, R., Fahey, D. W., Haywood, J., Lean, J., Lowe, D. C., Myhre, G., Nganga, J., Prinn, R., Raga, G., Schulz, M., and Dorland, R. V.: Changes in Atmospheric Constituents and in Radiative Forcing, in: Climate Change 2007: The Physical Science Basis, Contribution of Working Group I to the Fourth Assessment Report of the Intergovernmental Panel on ClimateChange, Cambridge University Press, Cambridge, UK and New York, NY, USA, 2007.

Forster, P. M. D. and Shine, K. P.: Radiative forcing and temperature trends from stratospheric ozone changes, J. Geophys. Res., 102, 10841-10855, doi:10.1029/96JD03510, 1997.

Galanter, M., Levy, H., and Carmichael, G. R.: Impacts of biomass burning on tropospheric $\mathrm{CO}, \mathrm{NO}_{x}$, and $\mathrm{O}_{3}$, J. Geophys. Res. 105, 6633-6653, doi:10.1029/1999JD901113, 2000.

Gauss, M., Myhre, G., Pitari, G., Prather, M. J., Isaksen, I. S. A., Berntsen, T. K., Brasseur, G. P., Dentener, F. J., Derwent, R. G., Hauglustaine, D. A., Horowitz, L. W., Jacob, D. J., Johnson, M., Law, K. S., Mickley, L. J., Müller, J.-F., Plantevin, P.H., Pyle, J. A., Rogers, H. L., Stevenson, D. S., Sundet, J. K., van Weele, M., and Wild, O.: Radiative forcing in the 21 st century due to ozone changes in the troposphere and the lower stratosphere, J. Geophys. Res., 108, 4292, doi:10.1029/2002JD002624, 2003.

Gazeaux, J., Clerbaux, C., George, M., Hadji-Lazaro, J., Kuttippurath, J., Coheur, P.-F., Hurtmans, D., Deshler, T., Kovilakam, M., Campbell, P., Guidard, V., Rabier, F., and Thépaut, J.-N.: Intercomparison of polar ozone profiles by IASI/MetOp sounder with 2010 Concordiasi ozonesonde observations, Atmos. Meas. Tech., 6, 613-620, doi:10.5194/amt-6-613-2013, 2013.

Hilton, F., Armante, R., August, T., Barnet, C., Bouchard, A., Camy-Peyret, C., Capelle, V., Clarisse, L., Clerbaux, C., Coheur, P.-F., Collard, A., Crevoisier, C., Dufour, G., Edwards, D., Faijan, F., Fourrié, N., Gambacorta, A., Goldberg, M., Guidard, V., Hurtmans, D., Illingworth, S., Jacquinet-Husson, N., Kerzenmacher, T., Klaes, D., Lavanant, L., Masiello, G., Matricardi, M., McNally, A., Newman, S., Pavelin, E., Payan, S., Péquignot, E., Peyridieu, S., Phulpin, T., Remedios, J., Schlüssel, P., Serio, C., Strow, L., Stubenrauch, C., Taylor, J., Tobin, D., Wolf, W., and Zhou, D.: Hyperspectral earth observation from IASI: five years of accomplishments, B. Am. Meteorol. Soc., 93, 347-370, doi:10.1175/BAMS-D-11-00027.1, 2011.

Hurtmans, D., Coheur, P.-F., Wespes, C., Clarisse, L., Scharf, O., Clerbaux, C., Hadji-Lazaro, J., George, M., and Turquety, S.: FORLI radiative transfer and retrieval code for IASI, J. Quant. Spectrosc. Ra., 113, 1391-1408, doi:10.1016/j.jqsrt.2012.02.036, 2012. 
Joiner, J., Schoeberl, M. R., Vasilkov, A. P., Oreopoulos, L., Platnick, S., Livesey, N. J., and Levelt, P. F.: Accurate satellitederived estimates of the tropospheric ozone impact on the global radiation budget, Atmos. Chem. Phys., 9, 4447-4465, doi:10.5194/acp-9-4447-2009, 2009.

Lacis, A. A., Wuebbles, D. J., and Logan, J. A.: Radiative forcing of climate by changes in the vertical distribution of ozone, J. Geophys. Res., 95, 9971-9981, doi:10.1029/JD095iD07p09971, 1990.

Li, J.: Gaussian quadrature and its application to infrared radiation, J. Atmos. Sci., 57, 753-765, 2000.

Li, Z.: On the angular correction of satellite radiation measurements: the performance of ERBE angular dependence model in the Arctic, Theor. Appl. Climatol., 54, 235-248, doi:10.1007/BF00865166, 1996.

Loeb, N. G., Manalo-Smith, N., Kato, S., Miller, W. F., Gupta, S. K., Minnis, P., and Wielicki, B. A.: Angular distribution models for top-of-atmosphere radiative flux estimation from the clouds and the earth's radiant energy system instrument on the tropical rainfall measuring mission satellite, Part I: Methodology, J. Appl. Meteorol., 42, 240-265, 2003.

Manney, G. L., Santee, M. L., Rex, M., Livesey, N. J., Pitts, M. C., Veefkind, P., Nash, E. R., Wohltmann, I., Lehmann, R., Froidevaux, L., Poole, L. R., Schoeberl, M. R., Haffner, D. P., Davies, J., Dorokhov, V., Gernandt, H., Johnson, B., Kivi, R., Kyro, E., Larsen, N., Levelt, P. F., Makshtas, A., McElroy, C. T., Nakajima, H., Parrondo, M. C., Tarasick, D. W., von der Gathen, P., Walker, K. A., and Zinoviev, N. S.: Unprecedented Arctic ozone loss in 2011, Nature, 478, 469-475, doi:10.1038/nature10556, 2011.

Martin, R. V., Jacob, D. J., Logan, J. A., Ziemke, J. M., and Washington, R.: Detection of a lightning influence on tropical tropospheric ozone, Geophys. Res. Lett., 27, 1639-1642, doi:10.1029/1999GL011181, 2000.

Myhre, G., Shindell, D., Bréon, F.-M., Collins, W., Fuglestvedt, J., Huang, J., Koch, D., Lamarque, J.-F., Lee, D., Mendoza, B., Nakajima, T., Robock, A., Stephens, G., Takemura, T., and Zhang, H.: Anthropogenic and natural radiative forcing, in: Climate Change 2013: The Physical Science Basis, Contribution of Working Group I to the Fifth Assessment Report of the Intergovernmental Panel on Climate Change, Cambridge University Press, Cambridge, UK and New York, NY, USA, 2013.

NOAA: Earth System Research Laboratory Global Monitoring Division (ESRL/GMD), Boulder, Colorado, USA, available at: http://www.esrl.noaa.gov/gmd (last access: 24 April 2015), 2015.

Ramaswamy, V., Boucher, O., Haigh, J., Hauglustaine, D., Haywood, J., Myhre, G., Nakajima, T., Shi, G. Y., and Solomon, S.: Radiative forcing in climate change, in: Climate Change 2001: The Scientific Basis. Contribution of Working Group I to the Third Assessment Report of The Intergovernmental Panel on climate change, Cambridge University Press, Cambridge, UK and New York, NY, USA, 2001.

Rodgers, C. D.: Inverse Methods for Atmospheric Sounding: Theory and Practice, World Scientific Publishing Co. Pte. Ltd., Signapore, 2, 2000.

Rothman, L., Jacquemart, D., Barbe, A., Benner, D. C., Birk, M., Brown, L., Carleer, M., Chackerian Jr., C., Chance, K., Coudert, L., Dana, V., Devi, V., Flaud, J.-M., Gamache, R., Goldman, A., Hartmann, J.-M., Jucks, K., Maki, A., Mandin, J.-Y.,
Massie, S., Orphal, J., Perrin, A., Rinsland, C., Smith, M., Tennyson, J., Tolchenov, R., Toth, R., Auwera, J. V., Varanasi, P., and Wagner, G.: The HITRAN 2004 molecular spectroscopic database, J. Quant. Spectrosc. Ra., 96, 139-204, doi:10.1016/j.jqsrt.2004.10.008, 2005.

Rothman, L., Gordon, I., Babikov, Y., Barbe, A., Benner, D. C., Bernath, P., Birk, M., Bizzocchi, L., Boudon, V., Brown, L., Campargue, A., Chance, K., Cohen, E., Coudert, L., Devi, V., Drouin, B., Fayt, A., Flaud, J.-M., Gamache, R., Harrison, J., Hartmann, J.-M., Hill, C., Hodges, J., Jacquemart, D., Jolly, A., Lamouroux, J., Roy, R. L., Li, G., Long, D., Lyulin, O., Mackie, C., Massie, S., Mikhailenko, S., Müller, H., Naumenko, O., Nikitin, A., Orphal, J., Perevalov, V., Perrin, A., Polovtseva, E., Richard, C., Smith, M., Starikova, E., Sung, K., Tashkun, S., Tennyson, J., Toon, G., Tyuterev, V., and Wagner, G.: The HITRAN2012 molecular spectroscopic database, J. Quant. Spectrosc. Ra., 130, 4-50, doi:10.1016/j.jqsrt.2013.07.002, 2013.

Safieddine, S., Boynard, A., Coheur, P.-F., Hurtmans, D., Pfister, G., Quennehen, B., Thomas, J. L., Raut, J.-C., Law, K. S., Klimont, Z., Hadji-Lazaro, J., George, M., and Clerbaux, C.: Summertime tropospheric ozone assessment over the Mediterranean region using the thermal infrared IASI/MetOp sounder and the WRF-Chem model, Atmos. Chem. Phys., 14, 1011910131, doi:10.5194/acp-14-10119-2014, 2014.

Sauvage, B., Martin, R. V., van Donkelaar, A., and Ziemke, J. R.: Quantification of the factors controlling tropical tropospheric ozone and the South Atlantic maximum, J. Geophys. Res., 11, D11309, doi:10.1029/2006JD008008, 2007.

Scannell, C., Hurtmans, D., Boynard, A., Hadji-Lazaro, J., George, M., Delcloo, A., Tuinder, O., Coheur, P.-F., and Clerbaux, C.: Antarctic ozone hole as observed by IASI/MetOp for 2008-2010, Atmos. Meas. Tech., 5, 123-139, doi:10.5194/amt5-123-2012, 2012.

Skeie, R. B., Berntsen, T. K., Myhre, G., Tanaka, K., Kvalevåg, M. M., and Hoyle, C. R.: Anthropogenic radiative forcing time series from pre-industrial times until 2010, Atmos. Chem. Phys., 11, 11827-11857, doi:10.5194/acp-1111827-2011, 2011.

Søvde, O. A., Hoyle, C. R., Myhre, G., and Isaksen, I. S. A.: The $\mathrm{HNO}_{3}$ forming branch of the $\mathrm{HO}_{2}+\mathrm{NO}$ reaction: pre-industrialto-present trends in atmospheric species and radiative forcings, Atmos. Chem. Phys., 11, 8929-8943, doi:10.5194/acp-11-89292011, 2011.

Stevenson, D. S., Young, P. J., Naik, V., Lamarque, J.-F., Shindell, D. T., Voulgarakis, A., Skeie, R. B., Dalsoren, S. B., Myhre, G., Berntsen, T. K., Folberth, G. A., Rumbold, S. T., Collins, W. J., MacKenzie, I. A., Doherty, R. M., Zeng, G., van Noije, T. P. C., Strunk, A., Bergmann, D., CameronSmith, P., Plummer, D. A., Strode, S. A., Horowitz, L., Lee, Y. H., Szopa, S., Sudo, K., Nagashima, T., Josse, B., Cionni, I., Righi, M., Eyring, V., Conley, A., Bowman, K. W., Wild, O., and Archibald, A.: Tropospheric ozone changes, radiative forcing and attribution to emissions in the Atmospheric Chemistry and Climate Model Intercomparison Project (ACCMIP), Atmos. Chem. Phys., 13, 3063-3085, doi:10.5194/acp-13-3063-2013, 2013.

Stolarski, R. S., Waugh, D. W., Wang, L., Oman, L. D., Douglass, A. R., and Newman, P. A.: Seasonal variation of ozone 
in the tropical lower stratosphere: southern tropics are different from northern tropics, J. Geophys. Res., 119, 6196-6206, doi:10.1002/2013JD021294, 2014.

Stubenrauch, C., Duvel, J.-P., and Kandel, R.: Determination of longwave anisotropic emission factors from combined broadand narrow-band radiance measurements, Adv. Space Res., 14, 103-107, doi:10.1016/0273-1177(94)90356-5, 1994.

Suttles, J. T., Green, R. N., Smith, G. L., Wielicki, B. A., Walker, I. J., Taylor, V. R., and Stowe, L. L.: Angular Radiation Model for Earth-Atmosphere System, Vol. II, NASA Ref. Public. 1184, NASA, Greenbelt, Md., USA, 1988.

Wespes, C., Emmons, L., Edwards, D. P., Hannigan, J., Hurtmans, D., Saunois, M., Coheur, P.-F., Clerbaux, C., Coffey, M. T., Batchelor, R. L., Lindenmaier, R., Strong, K., Weinheimer, A. J., Nowak, J. B., Ryerson, T. B., Crounse, J. D., and Wennberg, P. O.: Analysis of ozone and nitric acid in spring and summer Arctic pollution using aircraft, ground-based, satellite observations and MOZART-4 model: source attribution and partitioning, Atmos. Chem. Phys., 12, 237-259, doi:10.5194/acp12-237-2012, 2012.

WMO (World Meteorological Organization): Meteorology A Three-Dimensional Science: second Session of the Commission for Aerology, WMO Bulletin IV, WMO, Geneva, 134-138, 1957.
Worden, H. M., Bowman, K. W., Worden, J. R., Eldering, A., and Beer, R.: Satellite measurements of the clear-sky greenhouse effect from tropospheric ozone, Nat. Geosci., 1, 305-308, doi:10.1038/ngeo182, 2008.

Worden, H. M., Bowman, K. W., Kulawik, S. S., and Aghedo, A. M.: Sensitivity of outgoing longwave radiative flux to the global vertical distribution of ozone characterized by instantaneous radiative kernels from Aura-TES, J. Geophys. Res., 116, D03309, doi:10.1029/2006JD007258, 2011.

Ziemke, J. R., Chandra, S., Duncan, B. N., Schoeberl, M. R., Torres, O., Damon, M. R., and Bhartia, P. K.: Recent biomass burning in the tropics and related changes in tropospheric ozone, Geophys. Res. Lett., 36, L15819, doi:10.1029/2009GL039303, 2009.

Ziemke, J. R., Chandra, S., Labow, G. J., Bhartia, P. K., Froidevaux, L., and Witte, J. C.: A global climatology of tropospheric and stratospheric ozone derived from Aura OMI and MLS measurements, Atmos. Chem. Phys., 11, 9237-9251, doi:10.5194/acp-11-9237-2011, 2011. 